\title{
Surface-Water Quality-Assurance Plan for the California District of the U.S. Geological Survey
}

U.S. GEOLOGICAL SURVEY

Open-File Report 96-618

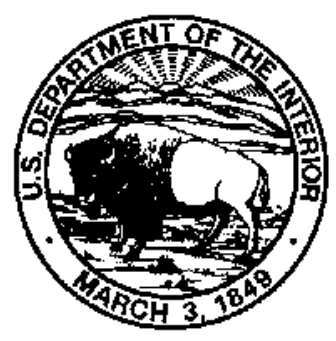





\section{Surface-Water Quality-Assurance Plan for the California District of the U.S. Geological Survey}

By Robert W. Meyer

U.S. GEOLOGICAL SURVEY

Open-File Report 96-618

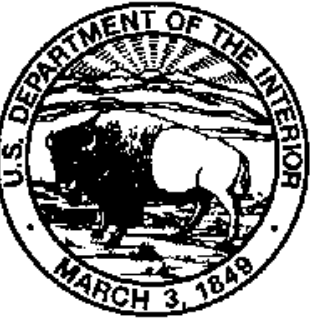




\section{U.S. DEPARTMENT OF THE INTERIOR BRUCE BABBITT, Secretary}

U.S. GEOLOGICAL SURVEY

Gordon P. Eaton, Director

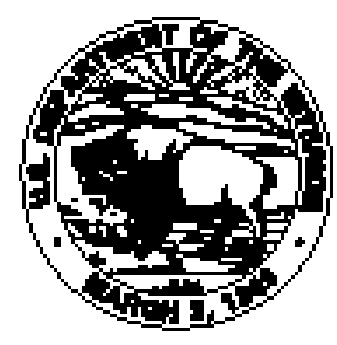

The use of firm, trade, and brand names in this report is for identification purposes only and does not constitute endorsement by the U.S. Geological Survey

For additional information write to:

District Chief

U.S. Geological Survey

Federal Building, Room W-2233

2800 Cottage Way

Sacramento, CA 95825
Copies of this report can be purchased from:

U.S. Geological Survey

Information Services

Box 25286

Federal Center

Denver, CO 80225 


\section{CONTENTS}

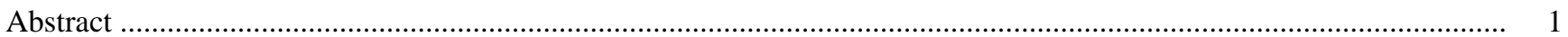

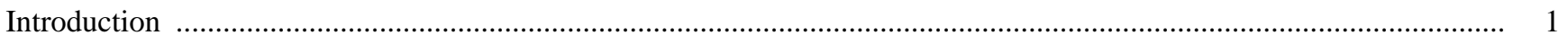

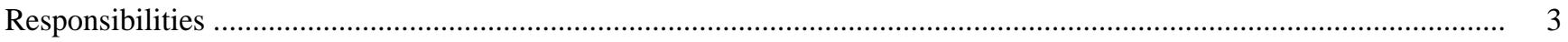

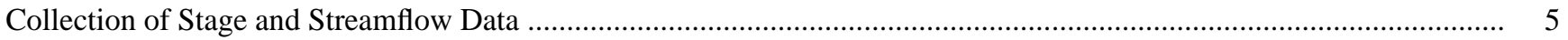

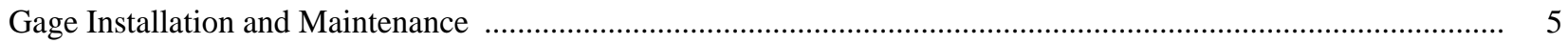

Measurement of Stage

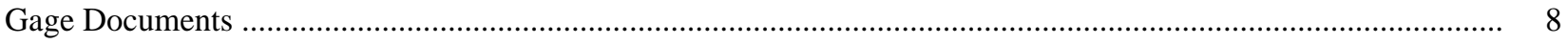

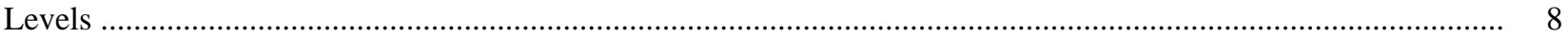

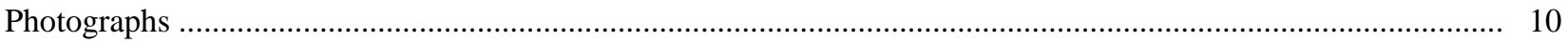

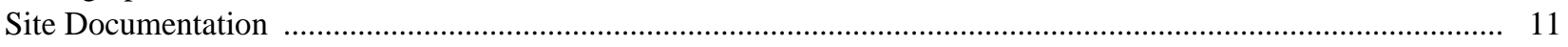

Documenting Establishment of New Surface-Water Stations ................................................................. 11

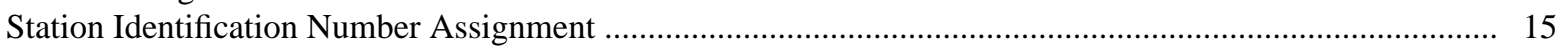

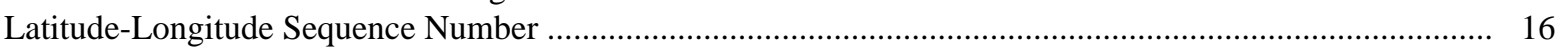

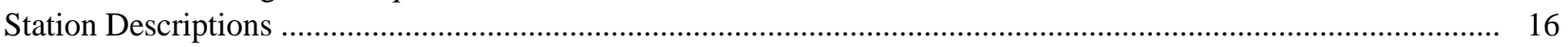

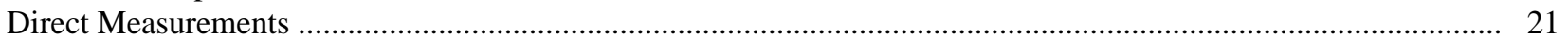

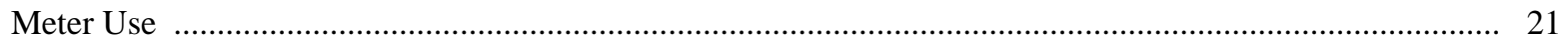

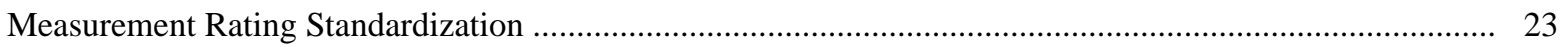

Number of Measurement Subsections ................................................................................................. 24

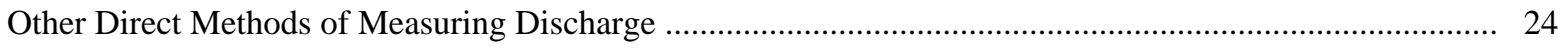

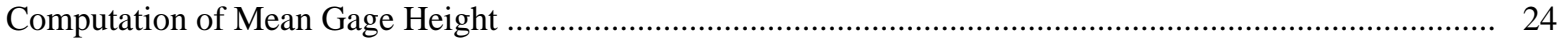

Check Measurements ............................................................................................................................ 24

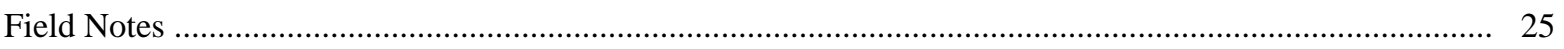

Discharge Measurement Note Guidelines ......................................................................................... 25

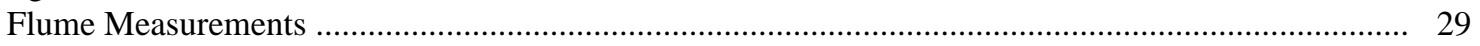

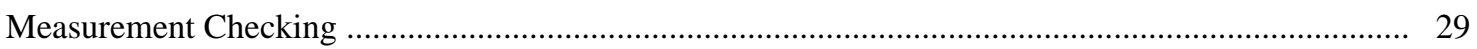

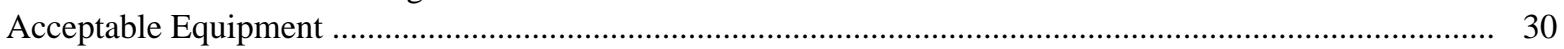

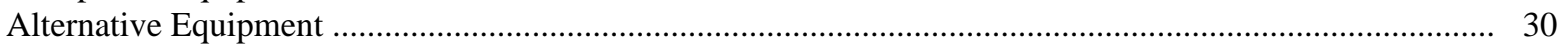

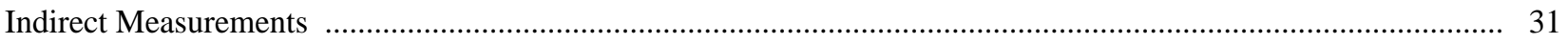

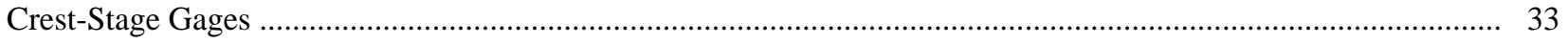

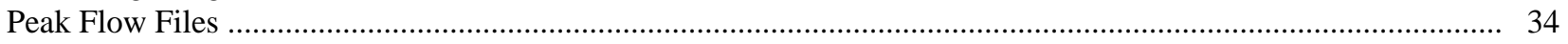

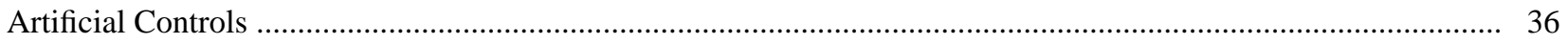

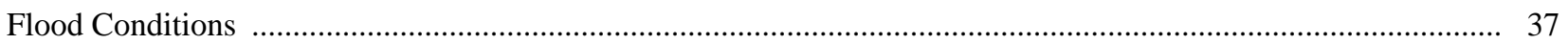

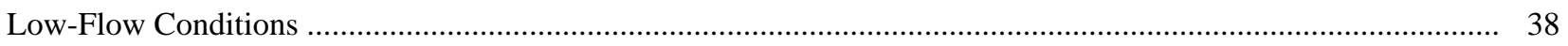

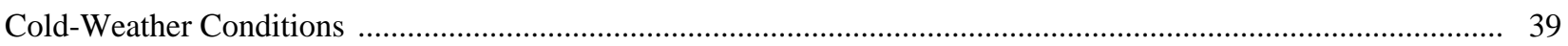

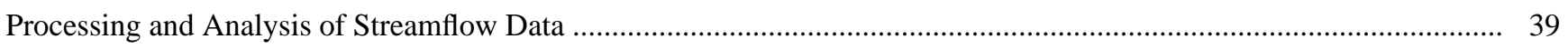

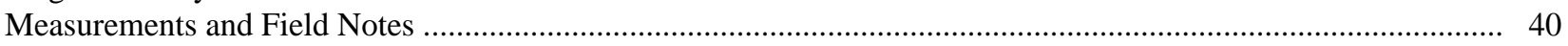

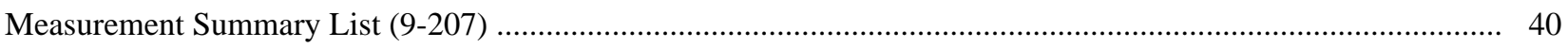

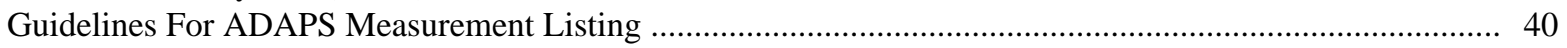

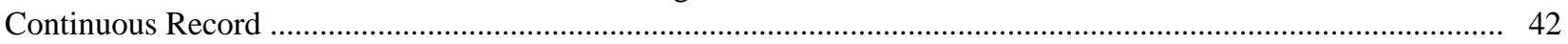

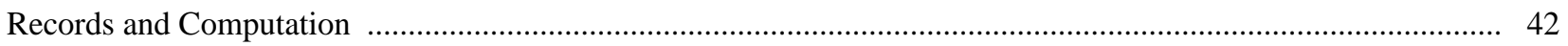

Procedures For Working and Checking Records ……......................................................................... 43

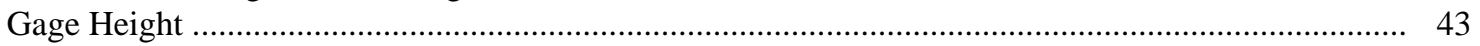

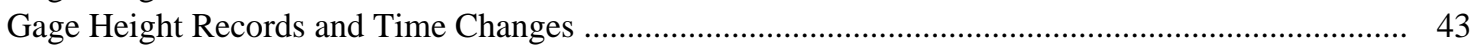

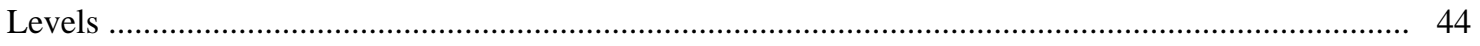

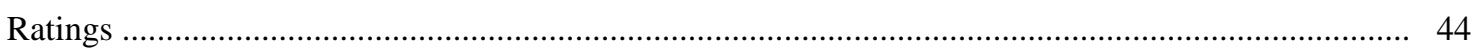

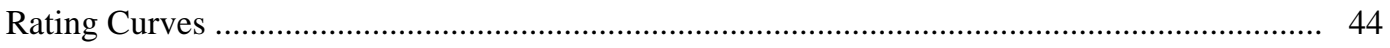

Rating Curve Master Sheet ………................................................................................ 45

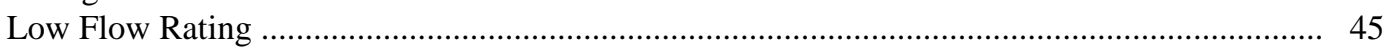


Scale Offset ..................................................................................................... 45

Curve Smoothness .................................................................................................... 45

High Flow Portion of Rating Curves ............................................................................... 46

Datum Corrections, Gage-height Corrections, and Shifts ........................................................ 46

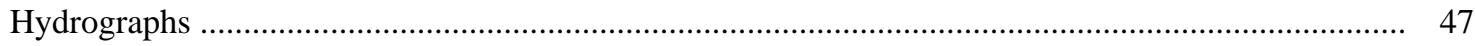

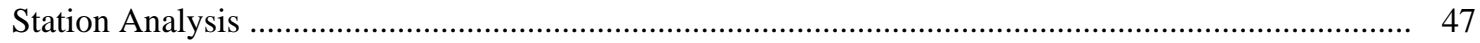

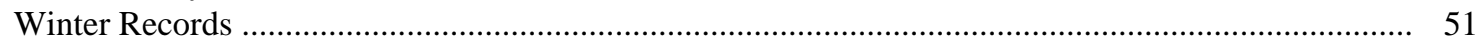

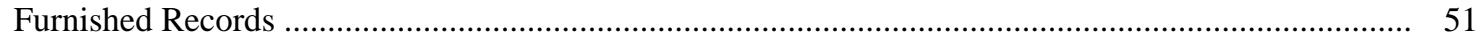

Review of Furnished Records ....................................................................................... 51

Federal Energy Regulatory Commission Records Review .............................................. 53

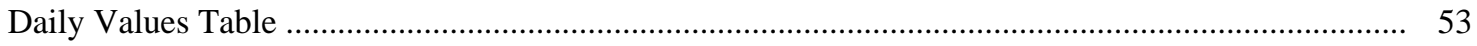

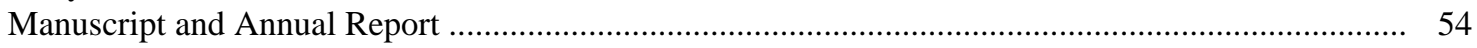

Review of Records .......................................................................................................... 54

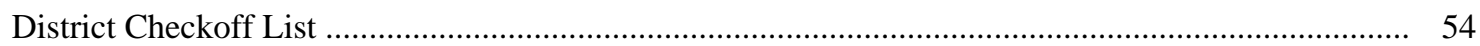

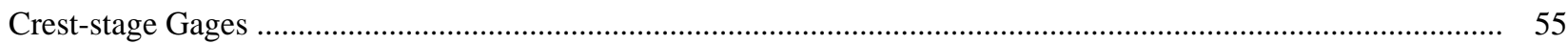

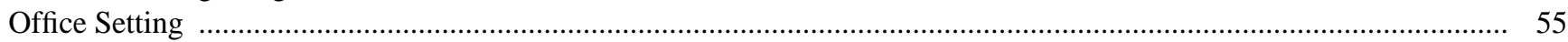

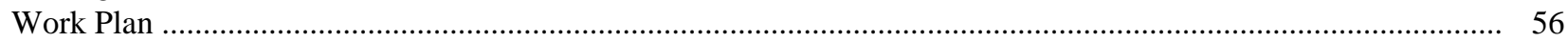

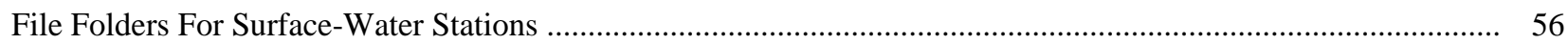

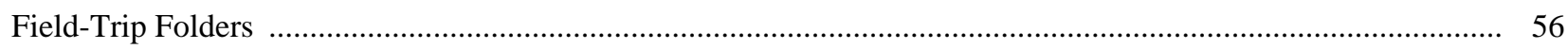

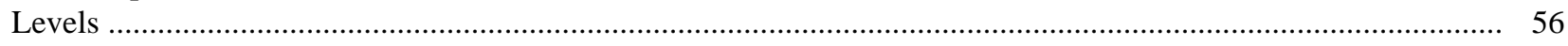

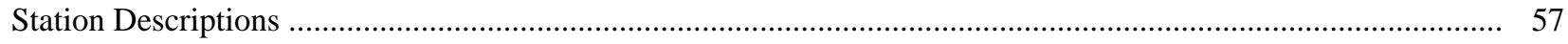

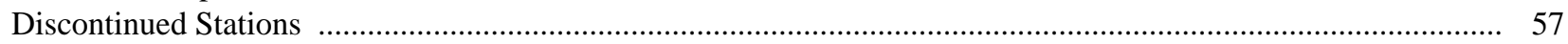

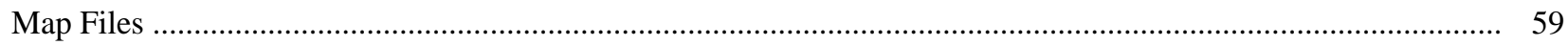

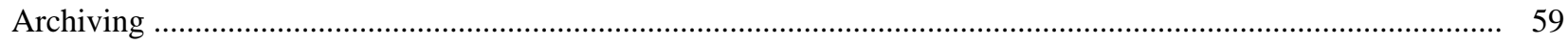

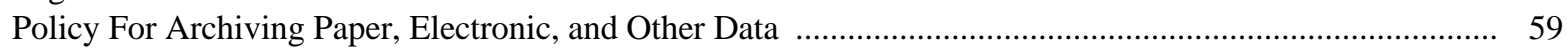

Communication of New Methods and Current Procedures ...................................................................... 62

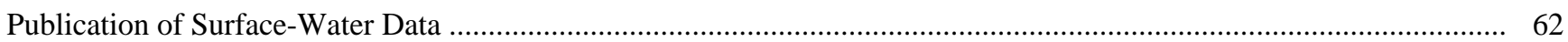

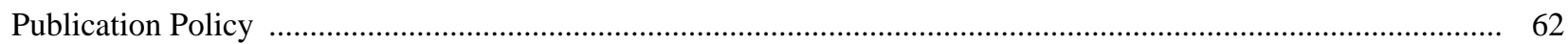

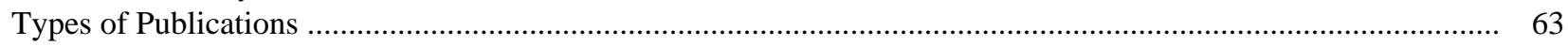

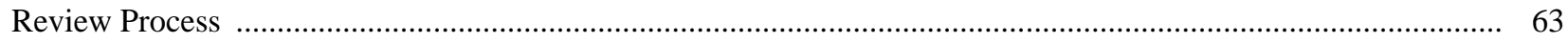

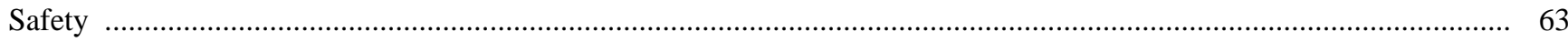

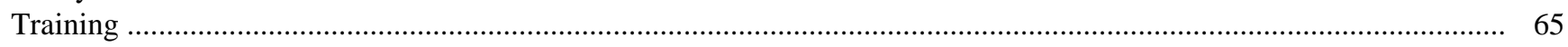

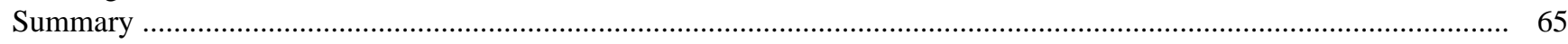

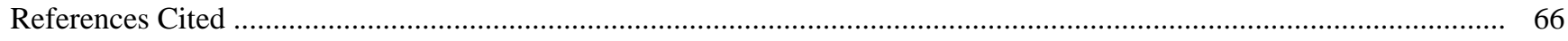

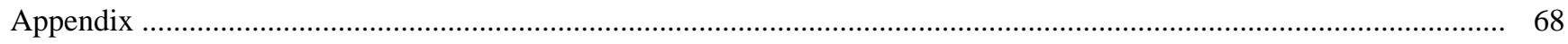

\section{FIGURES}

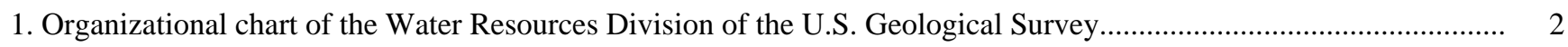

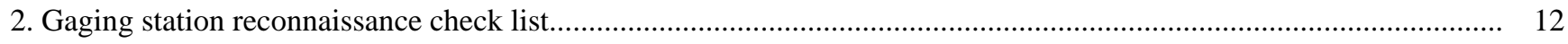

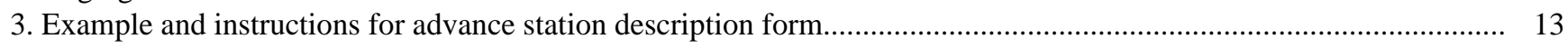

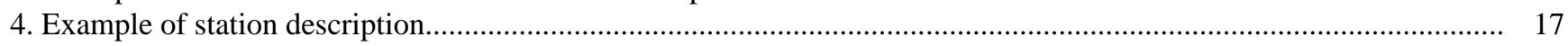

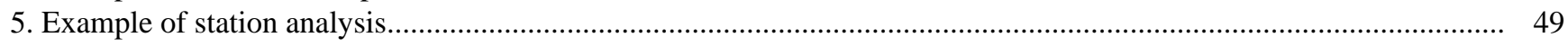

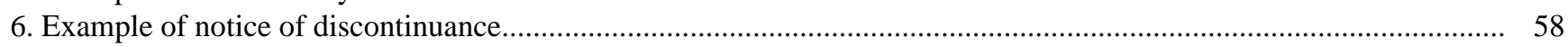

\section{TABLES}

1. Recommended guidelines for shifting. 
CONVERSION FACTORS AND ABBREVIATIONS

\begin{tabular}{rll}
\hline \multicolumn{1}{c}{ Multiply inch pound unit } & By & \multicolumn{1}{c}{ To obtain metric unit } \\
\hline acre & 0.405 & square hectometer \\
acre-foot (acre-ft) & 0.001233 & cubic hectometer \\
cubic foot per second $\left(\mathrm{ft}^{3} / \mathrm{s}\right)$ & 0.02832 & cubic meter per second \\
cubic yard ( $\left.\mathrm{yd}^{3}\right)$ & 0.7646 & cubic meter \\
foot (ft) & 0.3048 & meter \\
inch (in.) & 25.4 & millimeter \\
mile (mi) & 1.609 & kilometer \\
square mile (mi $\left.{ }^{2}\right)$ & 2.590 & square kilometer \\
yard (yd) & 0.9144 & meter \\
\hline
\end{tabular}

Temperature is given in degrees Fahrenheit $\left({ }^{\circ} \mathrm{F}\right)$ which can be converted to degrees Celsius $\left({ }^{\circ} \mathrm{C}\right)$ by the following equation and conversely:

$$
\text { Temp. }{ }^{\circ} \mathrm{C}=\left(\text { temp. }{ }^{\circ} \mathrm{F}-32\right) / 1.8
$$

Sea level: In this report, "sea level" refers to the National Geodetic Vertical Datum of 1929 (NGVD of 1929) - a geodetic datum derived from a general adjustment of the first-order level nets of both the United States and Canada, formerly called Sea Level Datum of 1929.

\section{ABBREVIATIONS AND ACRONYMS}

$\begin{array}{ll}\text { ADAPS } & \text { Automated Data Processing System } \\ \text { ADR } & \text { Analog-Digital Recorder } \\ \text { COOP } & \text { Cooperator } \\ \text { CSG } & \text { Crest-Stage Gage } \\ \text { DBM } & \text { Data Base Manager } \\ \text { DC } & \text { District Chief } \\ \text { DCPS } & \text { Data-collection Platform } \\ \text { DECODES } & \text { Device Conversion and Delivery System } \\ \text { FERC } & \text { Federal Energy Regulatory Commission } \\ \text { FOC } & \text { Field Office Chief } \\ \text { HT } & \text { Hydrologic Technician } \\ \text { ID } & \text { Identification } \\ \text { LT } & \text { Lead Technician } \\ \text { OC } & \text { Operation Chief } \\ \text { OJT } & \text { On-the-job Training } \\ \text { OSW } & \text { Office of Surface Water } \\ \text { PAB } & \text { Peak Above Base } \\ \text { PC } & \text { Project Chief } \\ \text { PZF } & \text { Point of Zero Flow } \\ \text { QA } & \text { Quality Assurance } \\ \text { QI } & \text { Quality Improvement } \\ \text { SWS } & \text { Surface Water Specialist } \\ \text { UV } & \text { Unit Values } \\ \text { WRD } & \text { Water Resources Division } \\ \text { PZF } & \text { Point of Zero Flow }\end{array}$




\title{
Surface-Water Quality-Assurance Plan for the California District of the U.S. Geological Survey
}

\author{
By Robert W. Meyer
}

\begin{abstract}
This Surface-Water Quality-Assurance Plan documents the standards, policies, and procedures to be used for activities related to the collection, processing, analysis, storage, and publication of surface-water data.
\end{abstract}

\section{INTRODUCTION}

The U.S. Geological Survey (USGS) was established by an act of Congress on March 3, 1879, to provide a permanent Federal agency to perform the systematic and scientific "classification of the public lands, and examination of the geologic structure, mineral resources, and products of the national domain." Surface-water activities in the California District are part of the Water Resources Division's (WRD) (fig. 1) overall mission of appraising the Nation's water resources. Surface-water information, including streamflow, stage, and sediment data, are used at the Federal, State, and local levels for resources planning and management.

The purpose of this Surface-Water Quality-Assurance Plan (QA Plan) is to document the standards, policies, and procedures used by the California District for activities related to the collection, processing, storage, and publication of surface-water data.

This plan identifies responsibilities for ensuring that stated policies and procedures are carried out. The plan also serves as a guide for all District personnel involved in surface-water activities and as a resource for identifying memorandums, publications, and other literature that describe in more detail associated techniques and requirements.

The scope of this report includes discussions of the policies and procedures followed by this District for the collection, processing, analysis, storage, and publication of surface-water data. Specific types of surface-water data include stage, streamflow, sediment, and basin characteristics. In addition, issues related to the management of the computer data base and employee safety and training are presented. Although procedures and products of interpretive projects are subject to the criteria presented in this report, specific interpretive projects are required to have a separate and complete quality-assurance plan.

This QA Plan is reviewed and revised at least once every 3 years in order that responsibilities and methodologies are kept current and in order that the ongoing procedural improvements can be effectively documented. 


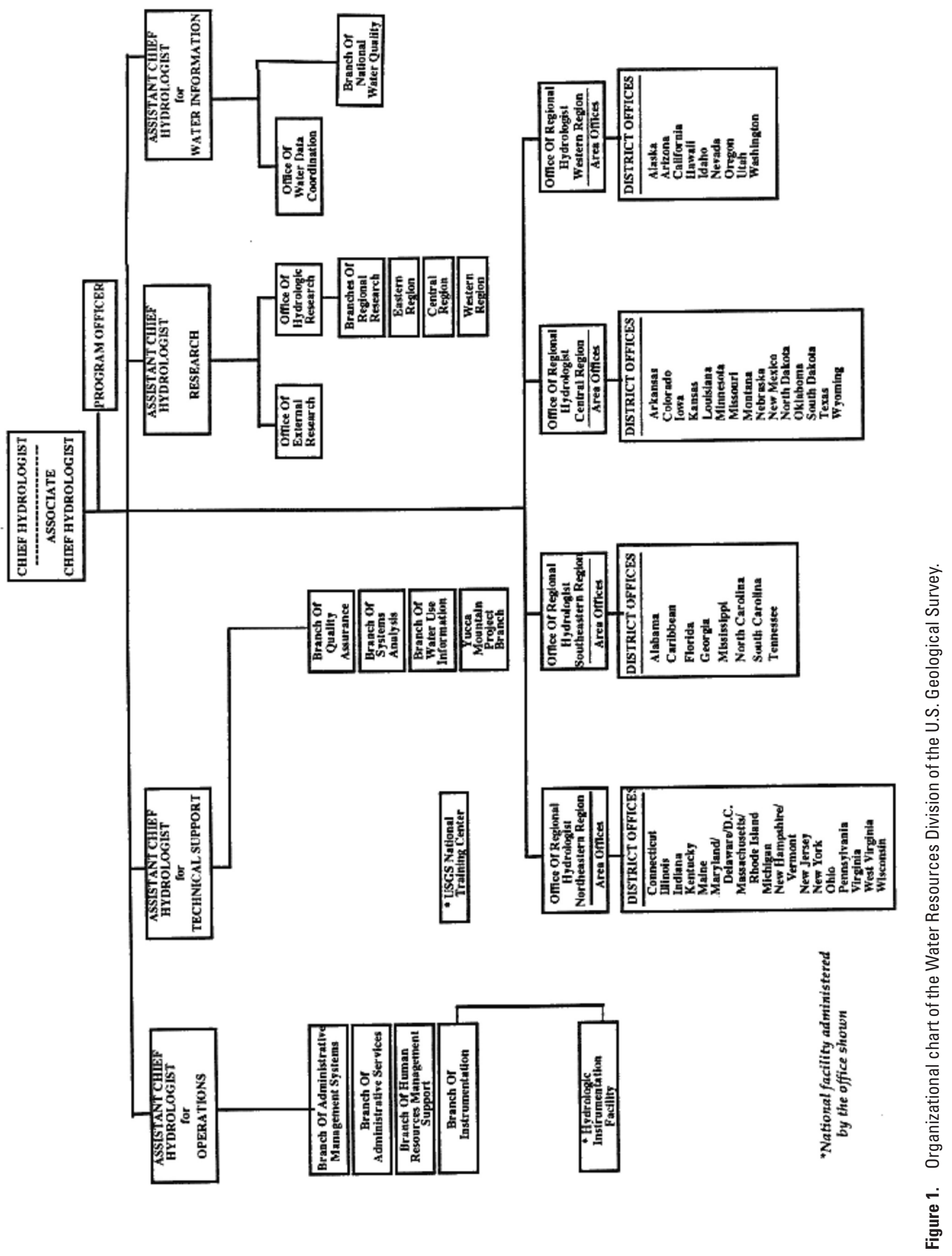




\section{RESPONSIBILITIES}

Quality assurance (QA) is an active process. Achieving and maintaining high-quality standards for surface-water data are accomplished by specific actions carried out by specific persons. Errors and deficiencies can result when individuals fail to carry out their responsibilities. Clear and specific statements of responsibilities promote an understanding of each person's duties in the overall process of assuring surface-water data quality.

The following is a list of responsibilities of District personnel involved in the collection, processing, analysis, storage, or publication of surface-water data.

The District Chief $(\mathrm{DC})$ is responsible for:

1. Managing and directing the District program, including all surface-water activities.

2. Ensuring that surface-water activities in the District meet the needs of the Federal government, the

California District, State and local agencies, other cooperating agencies, and the general public.

3. Ensuring that all aspects of this QA Plan are understood and followed by District personnel. This is accomplished by the District Chief's direct involvement or through clearly stated delegation of this responsibility to other personnel in the District.

4. Providing final resolution of any conflicts or disputes related to surface-water activities within the District.

5. Keeping subordinates briefed on procedural and technical communications from Regional Offices and Headquarters.

6. Performing technical reviews of all surface-water programs on a regular basis.

7. Ensuring that all publications and other technical communications released by the District are accurate and are in accord with USGS policy.

The Assistant District Chiefs are responsible for:

1. Assisting the DC in the scientific, technical, and administrative direction of all surface water resources programs of the District.

2. Making binding commitments for the district, implementing policies established by the DC.

3. Directing operations in the absence of the DC.

4. Supervising the District Discipline Specialists, the Computer Services Section, the Data Base Management Group, and the Reports Unit.

5. Advising the Regional and Chief Hydrologists on all phases of water resources in the State of California.

The Surface Water Specialist (SWS) - Quality Improvement Staff (QI) are responsible for:

1. Technically reviewing project proposals.

2. Reviewing Data Section and project surface-water data-collection methods. Reviews approximately 10 percent of computed surface-water records each year.

3. Providing technical training of Data Section and Project personnel as needed.

4. Providing quality review of data bases, such as ADAPS, Peak Files, Station Basin Characteristics.

5. Developing quality and/or continuous improvement plans.

6. Providing assistance or guidance as needed on indirect measurements of discharge. 
The Operations Chief (OC) is responsible for:

1. Providing technical leadership regarding techniques, methods and equipment for data-collection.

2. Maintaining a close working relationship with Field Office Chiefs.

3. Assuring data-collection and processing is in accordance with District, WRD and USGS policy.

4. Meeting with cooperators to ensure the data program is viable and fulfills the Survey mission.

The Field Office Chief (FOC) or Project Chief (PC) is responsible for:

1. Designing data-collection activities in the field area.

2. Assuring the accuracy of the gaging station records.

3. Providing leadership for staff members.

4. Maintaining expertise in all phases of data-collection, compilation, and computation.

5. Providing On-the-job training (OJT) and formal training for subordinates.

The Field Office Lead Technician (LT) is responsible for:

1. Assisting the FOC in the design of the data-collection activities.

2. Assisting the FOC in providing OJT in record computation, field work, and surveying.

3. Reviewing the field and record work of field technicians.

The Field Hydrologic Technician (HT) or Hydrologist is responsible for:

1. Correctly and accurately making discharge measurements of various types.

2. Installing, servicing, and repairing gaging station instruments.

3. Entering data retrieved from gaging station instruments into the ADAPS data base.

4. Developing ratings and entering them into ADAPS.

5. Computing discharge records and writing station descriptions and analyses.

6. Helping construct gaging facilities.

The Data Base Administrator is responsible for:

1. Supervising the Data Base Management staff and coordinating the section activities with other District units.

2. Providing technical assistance for National Water Information System (NWIS), Geographic Information Systems (GIS), and other data base systems.

3. Serving on committees of district, regional, and national scope for long-range data processing, storage, planning, and evaluating of hardware and software.

4. Developing and implementing plans and guidelines for the effective management and dissemination of hydrologic data in the District.

5. Working with project chiefs to ensure the development of data management plans for hydrologic investigations.

6. Directing, conducting, and assisting in training sessions and technical meetings.

The Data Base Management Computer Specialist is responsible for:

1. Checking the function of ADAPS, SATIN, and SENTRY each morning and correcting any discovered problems.

2. Creating all new sites in the data base.

3. Checking the Advance Station Description and map plots for completeness, assigning station ID's, delineating basin boundaries and digitizing to determine drainage area, and maintaining station records and maps. 
4. Maintaining DECODES and writing configurations for DCP's and data loggers.

5. Providing assistance as needed for routine ADAPS and DECODES questions from Project or Field Offices.

6. Maintaining DB tape archives, maintaining indices, and archiving unit value (UV) data and retrieving such data on request.

The Computer Section Management Team is responsible for:

1. Providing, maintaining, and enhancing computer resources, installing and upgrading WRD software, customizing software installations, and developing software for special processes or analysis of surface-water data.

2. Providing service and support for all surface-water-related projects and programs.

3. Procuring appropriate software and hardware to maintain inter-operability in support of data processing and analysis on dissimilar systems.

\section{COLLECTION OF STAGE AND STREAMFLOW DATA}

Many of society's daily activities, including industry, agriculture, energy production, waste disposal, and recreation, are closely linked to streamflow and water availability; therefore, reliable surface-water data are necessary for planning and resource management. The collection of stage and streamflow data is a primary component in the ongoing operation of streamflow-gaging stations (referred to in the remainder of this report as gaging stations) and other water-resource studies performed by the USGS and the California District.

The objective of operating a gaging station is to obtain a continuous record of stage and discharge at the site (Carter and Davidian, 1968, p. 1). A continuous record of stage is obtained by installing instruments that sense and record water-surface elevation in the stream. Discharge measurements are made at periodic intervals to define or verify the stage-discharge relation and to define the time and magnitude of variations in that relation.

It is the policy of this District that all (Data Section and Project) personnel involved in the collection of stage and discharge data shall be properly trained, well informed, and follow the surface-water datacollection policies and procedures established by WRD.

\section{Gage Installation and Maintenance}

Proper installation and maintenance of gaging stations are critical activities for ensuring quality in streamflow-data-collection and analysis. Effective site selection, correct design and construction, and regular maintenance of a gage can make the difference between efficient and accurate determination of drainage-basin discharge or time-consuming, poor estimations of flow.

Sites for installation of gaging stations are selected to meet specific data-collection needs. Additionally, sites should have, to the greatest extent possible, ideal hydraulic conditions. Criteria that describe the ideal gaging-station site are listed by Rantz and others (1982, p. 5). These criteria include unchanging natural controls that promote a stable stage-discharge relation, a satisfactory reach for measuring discharge throughout the range of stage, and the means for efficient access to the gage and measuring location. Other aspects of controls considered by District personnel when planning gage-house installations include those discussed by Kennedy (1984, p. 2). 
The individual responsible for selecting sites for new gaging stations is the FOC or PC, with assistance from the SWS or QI as needed. The process of site selection includes discussion with cooperators on the purpose of the gage, analysis of terrain with the use of topographic maps and aerial photography if available, field reconnaissance and detailed notes on the field reconnaissance form, and file search to determine if discontinued stations or partial record stations existed in the area. The responsibility for ensuring proper documentation of agreements with property owners is held by the respective FOC or PC. Approval of site design is the responsibility of the respective Chief, after consultation with the SWS or QI staff. Responsibility for construction of gages is held by the FOC or PC. Inspection and approval of the completed installation is the responsibility of the Chief.

A program of careful inspection and maintenance of gages and gage houses promotes the collection of reliable and accurate data. Allowing the equipment and structures to fall into disrepair can result in unreliable data and safety problems. It is District policy that a safety inspection of the gaging facility is performed at all sites by the FOC, PC, or designated Lead Technician once per year. To prevent the buildup of mud or the clogging of intakes, stilling wells are pumped as needed when determined by the responsible hydrologic technician. Other maintenance activities performed on a regular basis include cleaning of any surge suppression device attached to orifice lines at least once each year. Battery voltage and condition should be checked on a monthly basis.

It is the responsibility of the hydrologic technician to ensure that gages and gage houses are kept in good repair. The FOC or PC is responsible for ensuring that deficiencies are remedied.

\section{Measurement of Stage}

Many types of instruments are available for measuring the water level, or stage, at gaging stations. There are nonrecording gages (Rantz and others, 1982, p. 24) and recording gages (Rantz and others, 1982, p. 32). Because the uses to which stage data may be put cannot be predicted, it is Office of Surface Water (OSW) policy that surface-water stage records at stream sites be collected with instruments and procedures that provide sufficient accuracy to support computation of discharge from a stage-discharge relation, unless greater accuracy is required (OSW memorandum 93.07).

In general, operation of gaging stations for the purpose of determining daily discharge includes the goal of collecting stage data at the accuracy of + or - 0.01 foot (OSW memorandum 89.08). An explanation of WRD policy on stage-measurement accuracy as it relates to instrumentation is provided in OSW memorandum 93.07.

The types of instrumentation installed at any specific gage house operated by the California District is dependent on the needs of the cooperator, the availability of utility lines, terrain, the expected range of stage, channel type, real-time data requirements, and accessibility. Types of water-level recorders operated by personnel in this District may include A-35 \& A-71 analog recorders, ADR's, and many types of electronic data loggers.

The responsibility for determining what type of water-level recorders are operated at each gaging station is held by the FOC or PC. Ensuring that new equipment has been installed correctly is the responsibility of the respective Chief. Proper maintenance of gage instrumentation or replacement, if appropriate, of equipment is the responsibility of field personnel who service the gage. 
A common weakness of the bubbler-type gage is its inability to keep up with a fast-rising stream. The bubble gage also tends to register low when there is a heavy surge. The main problem, however, is that there is no Dahman Peak Indicator reading or well High Water Mark to fall back on when the recorder or manometer malfunctions. Outside High Water Marks are sometimes available, but not as often as desired.

In order to assure knowledge of peaks at bubble gage installations, a crest-stage gage (CSG) will be installed whenever such a station is built. For those stations already in operation, a CSG will be installed as soon as practicable. The CSG should be able to record all peaks above the selected base peak discharge.

Accurate stage measurement requires not only accurate instrumentation but also proper installation and continual monitoring of all system components to ensure the accuracy does not deteriorate with time (OSW memorandum 93.07). To ensure that instruments, located within the gage house, record water levels that accurately represent the water levels of the body of water being investigated, "inside" and "outside" water-level readings are obtained by independent means.

The inside gage readings do not necessarily always equal outside readings, especially if the gages are not in the same pool at all ranges of stage. At stations equipped with a stilling well, the base or reference gage usually is an instrument installed inside the gage house. Other gages are installed outside the gage house to indicate whether or not the intakes are operating properly (Rantz and others, 1982, p. 53 and p. 64)

At each gaging station, the staff gage least prone to accidental datum changes is designated the "reference gage". For stations with stilling wells, the reference gage is the staff gage in the well. If the stilling well is too small to have an inside staff, then the outside staff serves as the reference gage. Because inside staffs are usually inconvenient to read, another gage-height indicator, preferably the ADR dial, or tape gage pointer, is designated the "principal gage". The principal gage reading is used to determine the mean gage-heights of discharge measurements, and is used to set the recorder pen if there is a graphic recorder backing up the ADR. If there is a graphic recorder and no ADR or data logger, the tape gage pointer becomes the principal gage. The inside staff or reference gage should be read at least every 3 months, and the principal gage should be reset to agree with the reference gage, if the difference is clearly 0.01 feet or more.

At bubble-gage and pressure transducer installations, the reference gage should be a sturdy low- water section of outside staff gage near the orifice. The principal gage will be the counter on the manometer, or the readout for the transducer. Generally, the instrument should be reset to the reference gage only when the stage in the stream is low and there is no wind or wave action, and there is minimal pile-up or drawdown around the reference gage. At high stages, the instruments usually are a more reliable index of gage height than the upper staff readings. Significant gage-height differences can be corrected later with datum adjustments if analysis shows that the instrument was truly in error.

Personnel servicing the gage are responsible for comparing inside and outside readings during each site visit to determine if the outside water level is being represented correctly by the gages. If a deficiency is identified, the personnel servicing the gage are responsible for thoroughly documenting the problem on the field note sheet and either correcting the problem immediately or contacting the FOC, LT or PC so that corrective actions can be taken at the earliest opportunity. 
Ensuring that instrumentation installed at gaging stations is properly serviced and calibrated is the responsibility of the field technician. This responsibility is accomplished by inspection of the gage height record, and comparison to past and current outside gage heights during station visits. If an erratic or missing data record is identified, the HT is expected to repair or correct the problem. Extra instruments and parts sufficient to make the majority of repairs or replacements are carried in each field vehicle. In cases where the HT cannot effect a correction or repair, a phone call to the LT or FOC for further instruction for proper calibration or repair procedures should be made before leaving the gage area. The HT is responsible for making repairs or corrections, with additional training as needed.

It is worth emphasizing that if the field technician, on visiting a station after a peak, finds that the primary recorder has malfunctioned, special attention should be given to checking the A-35 reversal correction and locating outside HWM's, marks in the well, and CSG marks. The field person should check the reversal mechanism of the A-35 every visit during the high-water season to make sure the pen will reverse properly.

\section{Gage Documents}

It is District policy that certain documents are placed in each gage house for the purpose of keeping an on-site record of observations, equipment maintenance, structural maintenance, and other information helpful to field personnel. Documents maintained at each gage house include: (1) the most recent digital stage-discharge relation (rating table); (2) a graph of the rating upon which each new measurement is plotted; (3) the most recent station description (see the section "Site Documentation, Station Description" in this report); (4) a log updated by field personnel upon each site visit describing control conditions and listing gage readings, measurement values, gage-house maintenance, and equipment maintenance; (5) a calendar; and (6) important telephone numbers.

It is the responsibility of personnel who run a field trip regularly, to exchange outdated material with updated gage documents as needed. When field personnel visit a gage house and identify a need to update one or more of the documents, that person is responsible for making sure an updated version is obtained and placed in the gage within the next calendar quarter. Individuals having questions related to what documents should be kept in a gage house, when the documents should be replaced with newer documents, or appropriate methods of appending logs or plotting measurements should contact the FOC or PC.

\section{Levels}

The various gages at a gaging station are set to register the height of a water surface above a selected level reference surface called the gage datum. The gage's supporting structures--stilling wells, backings, shelters, bridges, and other structures--tend to settle or rise as a result of earth movement, static or dynamic loads, vibration, or battering by floodwaters and flood-borne ice or debris. Vertical movement of a structure makes the attached gages read too high or too low and, if the errors go undetected, may lead to increased uncertainties in streamflow records. Leveling, a procedure by which surveying instruments are used to determine the differences in altitude between points, is used to set the gages and to check them from time to time for vertical movement (Kennedy, 1990, p. 1). Levels are run periodically to all bench marks, reference marks, reference points, and gages at each station for the purpose of determining if any datum changes have occurred (Rantz and others, 1982, p. 545).

The purpose of these instructions is to set uniform procedures for the collection and recording of differential leveling data at gaging stations. 
1. Every gaging station will have at least one complete level circuit every three years. If the gage or the Reference Marks (RM's) are found to be unstable, then annual or more frequent circuits will be run. (Every effort should be made to establish a stable RM). At a new station, run levels when establishing the gage, with another complete circuit the next year. If there are no significant discrepancies, go to the three-year cycle (Kennedy, 1990, p. 14, and OSW memorandum 90.10)

2. Levels are run by use of field methods and documentation methods described by Kennedy (1990). Level procedures followed by District personnel pertaining to circuit closure, instrument reset, and repeated use of turning points are described by Kennedy (1990) and in OSW memorandum 93.12. The level instruments are kept in proper adjustment by the peg test described by Kennedy (1990, p. 13).

3. A two-peg test will be performed at least once per week while doing leveling, and as necessary, whenever there is reason to doubt instrument performance. The error found with the test should not exceed 0.003 feet in 100 feet of distance.

4. Every level circuit with two or more turning points will be a closed loop. This means that the starting point of a level circuit must also be the finishing point. The reference gage must be a turning point in the level network. For a station where all reference marks (RM) and gages may be shot from a single point, move the instrument and shoot all points again. The rod person will use a rod level, and rod readings should be recorded to 0.001 feet.

5. When running the level circuit, the elevations of all reference marks, outside staffs, inside staffs, wire weights, reference points, orifice tips, water surface, and if possible, the point of zero flow will be determined.

6. The low-water section of the primary reference gage will be reset if it is in error by more than 0.015 feet with respect to the base RM. Other gage sections may be in error by as much as 0.03 feet before resetting is mandatory.

7. There should be 3 RM's at each gage:

a. One RM near the gage house

b. One RM above major peak gage heights

c. One RM, at a location beyond the reach of a catastrophic flood.

The purpose of this RM is to provide a point from which the original gage station can be reestablished in the event that the station and/or nearby RM's are destroyed. Reference Marks (RM's) should never be renumbered, nor should a lost or destroyed RM number ever be used again. If a lost RM is recovered, the original number is to be used.

8. Rod length will be checked with a steel ruler. This is not required for each circuit, but should be done when a two-peg test is made, or whenever rod damage is suspected.

9. A 25-foot fiberglass telescoping rod will not be used for gaging station levels. It is not sufficiently accurate. 
10. It is the responsibility of the FOC or PC to ensure that level notes are checked. The level information is entered on the level-summary form by the technician in charge of the field party. Ensuring that levels are run correctly and that all level notes are completed correctly is the responsibility of the chief of field party. Ensuring that levels are run at the appropriate frequency is the responsibility of the FOC or PC.

11. Field notes are as important as the actual field techniques. They constitute an official, permanent record of the survey and must be in a format that is easily interpreted by a reviewer or anyone familiar with the type of work done. All field notes must be recorded in the field at the time of the survey. Notes from memory are not acceptable. Notes should be complete and should contain all necessary information. A good sketch of the site may be helpful in interpreting the notes at a later date. While there is no specifically correct format for level notes, standard methods are outlined in various surveying textbooks, and good examples of level notes using USGS notepaper, Form 9-276, are shown by Kennedy (1990).

12. All active gages will have a chronological summary sheet of all level circuits at the station. This summary is kept in the permanent records file.

13. Due to inherent errors, a wire-weight gage may not read accurately at low water if it is set to the check bar (CB) elevation. Errors in low-water readings can amount to several hundredths when the $\mathrm{CB}$ is set to read the same as the $\mathrm{CB}$ elevation. The correct $\mathrm{CB}$ reading is to be determined using the method outlined by Kennedy (1990).

14. At servo-manometer and pressure transducer gaging stations, keeping "on datum" is a matter of checking and resetting the outside staff gage by levels. In this case, the outside staff is the only reference gage. After checking the staff gage, the procedure is to read the gage counter, dial, or read out, record it in notes, and set the gage indicator to read the same as the staff gage. If the reference staff gage is susceptible to damage, it should be checked by levels annually or more often if conditions warrant. All adjoining staff plates should be checked with steel rules at the time of leveling.

15. If a Bench Mark is reasonably close (3 miles or less), an effort should be made to tie the gage into the National Geodetic Vertical Datum. Begin at the "base" RM at the gage, using the gage datum elevation, and run a closed loop to the BM. Double-rodded leveling may be used if proper procedures are followed. If double-rodding is used, it is critical that the fore sights and back sights are balanced, and that the level is in good adjustment.

\section{Photographs}

Photographs of newly installed gage houses, station controls, possible indirect measurement sites, reference marks, and damaged structures are made by field personnel for the purpose of documenting gagehouse construction, changes in control conditions, or to supplement various forms of written descriptions. Cameras are made available by the FOC or PC as needed. Each photograph that becomes part of the station record is identified by writing the station number, name, and date on the back of the photograph with a permanent-ink marker. Photographs are placed in station photo files. 


\section{Site Documentation}

Thorough documentation of qualitative and quantitative information describing each gaging station is required. This documentation, in the form of a station description and photographs, provides a permanent historic record of site characteristics, structures, equipment, instrumentation, altitudes, location, and changes in conditions at each site. Information pertaining to where these forms of documentation are maintained is discussed in the section of this report entitled "Office Setting."

A station description is prepared for each gaging station, water quality, or sediment data-collection site and becomes part of the permanent record for each station. It is District policy that the station description is written no later than 8 weeks after the station is established. The responsibility for ensuring that station descriptions are prepared correctly and in a timely manner is held by the FOC or PC. A reconnaissance form is to be filled out during site selection.

\section{Documenting establishment of new surface-water stations}

In the process of establishing a new surface-water data-collection station or reestablishing an old station, the following steps should be taken to make a record of site evaluation and to insure assignment of downstream order number, entry into the District's Master and Active Station Lists, and creation of necessary National Water Information System (NWIS) Files.

1. Field or project office personnel should complete a Gaging Station Reconnaissance Checklist (fig. 2) to document the conditions at a proposed streamflow gage site. It will provide a summary of the site evaluation, including potential problems. Much of the data included on the form will be beneficial when the actual station description is written. This field form is located in the District PR1ME file OPERATIONS>ADV.STA.DESC>FIELD.FORM. Waterproof forms can also be obtained from the Quality Improvement Section. After this form is completed in the field, it should be transmitted to the Quality Improvement Section for review.

2. Once the site location has been finalized, the field or project office should prepare and send by electronic mail a copy of the Advance Station Description to the District DBM computer specialist. A paper copy of the Advance Station Description should also be sent to accompany the location map (2.n. below). This information should be entered on a copy of the Advance Station Description Form located in OPERATIONS > ADV.STA.DESC >ADV.FORM or in the WordMARC document CREATE option. This form (fig. 3) should contain as much of the following as possible:

a. Station number--if station is being reestablished, give previously assigned station number. For new stations or if number is in question, leave blank and number will be determined by the DBM computer specialist. Be sure to provide all necessary information in the "Downstream order information" section. California District Instruction Number 1100.001 gives criteria for station identification number assignment to new stations, and pages 50-51 of "WRD Data Reports Preparation Guide" (Novak, 1985) give criteria for determining equivalence of record. b. Station name--if station is being reestablished, give previously assigned name. For new stations, refer to "WRD Data Reports Preparation Guide (Novak, 1985)," pages 37-39, for selection of names.

c. Location--include latitude/longitude, quarter sections, township/range, county, hydrologic unit code, name and scale of topographic map, and description in format exactly as it will be published in the Annual Data Report; refer to "WRD Data Reports Preparation Guide (1985). 


\section{Gaging Station Reconnaissance Checklist}

Personnel making recon:

Date:

Name of river:

At Near

The land owner is:

Permission for gage obtained: $\square$ yes $\square$ no $\quad(\square$ verbal $\square$ written )

What reach of channel was recon limited to: miles upstream, and miles downstream, from site selected.

Are there alternate sites? $\square$ yes $\square$ no.

Are there any old gaging station sites in the vicinity? $\square$ yes $\square$ no.

If yes, was old site investigated? $\square$ yes $\square$ no.

Explain in detail why old site will not be used, including reason for discontinuance, on back of form.

$\square$ Site has been observed when flow was: $\square$ low $\square$ moderate $\square$ high.

$\checkmark$ Site identified on topographic map. Quad name:

Photographs made of site, including bed material, obstruction(s) to flow, view downstream from proposed gage site, overbank area, meas. bridge.

$\square$ Sketch made of gage reach, including the low and high-water controls, cable section, the type and distribution of vegetation, obstructions etc.

Type of gage planned: $\square$ Well $\square$ Manometer $\square$ AVM $\square$

Do you anticipate building an artificial control? $\square$ yes $\square$ no.

If yes, describe the control in detail on back of form.

High flow measurements will be made by or from:

$\square$ Bridge $\square$ Cableway $\square$ Indirect $\square$ Optical $\square$ Other:

Is there a usable indirect measurement site? $\square$ yes $\square$ no.

If yes, describe location in detail on back of form.

Is the gage reach suitable for a step-backwater computation $\square$ yes $\square$ no.

If no, what other technique will be used to develop initial rating curve?

Do you anticipate problems with:

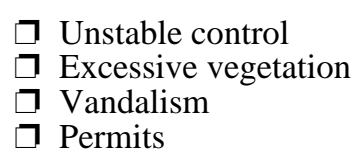

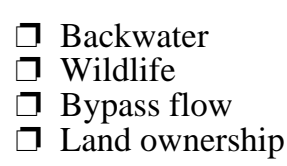

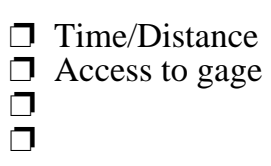

Copies of topographic map, sketch, photographs, and this form provided to District Quality Assurance staff.

Figure 2. Gaging station reconnaissance checklist. This form is a 5X8 inch water proof field sheet. The front is shown and the back will be blank lines for notes. The inside of this hinged form is blank for sketches. The Reconnaissance form provides critical information used in completing the station description and helps insure that good or bad gaging sites are identified. 


\section{ADVANCE STATION DESCRIPTION OF GAGING STATION}

$\square$ New Station $\square$ Reestablished Station

Part: __ Basin: Station Number:

Station Name:

Location: Lat: Long: ___ _ 1/4 _ 1/4 Sec:_ T:_ R:_County: Long: ___ _ 1/4 _ 1/4 Sec:_ T:_ R:_County:

Scale: 1: Description: Hydrologic Unit Code: ___ Quad Name:

Date established: Drainage area: (Date of first published equivalent record)

Elevation of gage: square miles $\square$ Needed $\square$ Not to be determined $\square$ Indeterminate

Above items checked and confirmed by SW site file coordinator: Name: Date:

Equipment and data-collection:

$\square$ Stilling Well $\square$ Manometer $\square$ Water-Quality Monitor $\square$ Crest-Stage Gage $\square$ Other:

Period of data-collection: $\square$ all year $\square$ seasonal $\square$ intermittent

Range of data-collection: $\square$ all stages $\square$ high flow $\square$ low flow

Digital Recorder: $\square$ ADR $\square$ Data Logger $\square$ DCP $\square$ None $\square$ Other:

Recording interval: _ _ min data Format: $\square$ Real $\square$ Integer (enter "V" for variable)

Recorded Parameters: For multiparameter recorder, list in order recorded. For multi-parameter ADR, is first digit recorded the channel number? $\square$ Yes $\square$ No Parameter Name Parameter Code1:

Telemetry: $\square$ None $\square$ Land line $\square$ Radio $\square$ Satellite

Graphic Recorder: $\square$ Yes Parameter: 2:__ 3:

Supplemental Records (not continuously recorded): $\square$ Water Quality $\square$ Daily sediment $\square$ Periodic Sediment $\square$ Other:

Publication status: $\square$ Annual Report, Volume Number: _ $\square$ Project Report Type: $\square$ Open-File $\square$ WRI $\square$ other: $\square$ Not Published, Why not:

Cooperator:Name: Financing: $\square$ Coop

Coop Full-Repay $\square$ OFA $\square$ FERC $\square$ Other:

District Account Number:4706-

Justification/Purpose of Gage:

Remarks:

Date station map plot sent:

Downstream order information:

Prepared by:

Date:

Instructions for advance station description form:

1. Copy the file OPERATIONS>ADV.STA.DESC >ADV.FORM into your directory or use the form file in CREATE option of WordMARC. These files are in ASCII format in order to allow email.

2. Fill blank fields and check boxes ([ ] ) using WordMARC in the overwrite (as opposed to the insert) mode. In unformatted fields, extra lines can be added as necessary, but limit line length to 78 columns. Portions of the form can be copied to allow multiple entries (e.g., More than one digital recorder).

3. These instructions will appear at the top of the blank form in the OPERATIONS directory or in the WordMARC CREATE menu, so upon completion delete the instructions.

4. Email a copy of the completed file to the DBM Computer Specialist.

Figure 3. Example and instructions for Advance station description form. 
d. Date established--show date of first record published by USGS that is equivalent to present record. If a new site, show date of first record to be published.

e. Drainage area--if no drainage area is given, indicate whether it needs to be determined by the DBM computer specialist, does not need to be determined, or whether it is indeterminate (cannot be defined).

f. Elevation of gage--give the physical elevation of the gage site. For streamflow stations, use the approximate point of zero flow in the stream channel. For reservoir stations, use the invert of the outlet. In most cases, this value is not the same as the datum of the gage.

g. Equipment and data-collection--indicate types of data-collection devices, periods and ranges of stage for which data will be collected, types of recorders (ADR, DCP, CR10, graphic, etc.), recording intervals $(5,15,30,60$ etc. minutes, variable), data formats (eg. dial readings in integers from ADR or real numbers with decimal points from CR10), and the names and codes of the parameters recorded. If a multi-parameter recorder, give the order in which the parameters occur, and for a multi-parameter ADR, indicate if the first digit recorded is the channel number.

h. Supplemental records--list other data to be collected on a recurring schedule, but not continuously recorded, such as water quality, periodic or daily sediment, etc.

i. Publication status--indicate which volume in annual report, open-file or project report, or not published.

j. Cooperator/Financing details--indicate cooperator name and funding, such as coop, coop fullrepay, OFA, FERC, etc.

k. District Account Number--indicate the 5-digit account number after the 4706 District code (eg. 4706-00113 or 4706-46900).

1. Justification--describe the purpose of this new site, such as watermaster need, local water management, rainfall/runoff study, etc.

$\mathrm{m}$. Remarks--include anything that will provide more information on this site, such as previous records collected at this site, site previously operated by another agency, etc.

n. Date station map plot sent--print of the section of the topographic map with the station location clearly marked. This must be sent to the DBM computer specialist in order for the drainage area to be determined. Include a paper copy of the completed Advance Station Description with the map. If it is a reestablished station, include a copy of the most recent station description. Indicate the date the material was sent.

o. Downstream order information--list any stations immediately upstream and downstream from new gage site, including discontinued stations if known.

There have been separate Advance Station Description forms for standard downstream order stations and other stations only identified by latitude and longitude. Both types of stations will use the same Advance Station Description form discussed herein. If some of the drainage boundaries of the site are not clearly defined on topographic maps, the field or project office should furnish a map indicating where the uncertain boundaries should be drawn. The originating office need not outline the entire basin unless it cannot be determined from the topographic map. 
3. The DBM computer specialist will assign a station number and determine the drainage area, as necessary. NOTE: Drainage areas will not be determined until an Advance Station Description has been provided. The "WRD Data Reports Preparation Guide (Novak, 1985)", pages 43-46, provides guidelines for the determination of drainage area. For any sites that include drainage area outside of the State of California or are located in the State but outside of the District's operational boundaries, the coordinator will contact the other District(s) involved in order to coordinate station number selection and drainage area determination.

4. The DBM computer specialist will update the District's Master List. All established sites that have relevance to determination of station numbers or drainage area within the State of California or within the District's operational boundaries will be included in the Master List of surface water sites.

5. The DBM computer specialist will establish the NWIS Site File for any new site which will be processing and/or storing data in the NWIS or WATSTORE systems. Sites not using these data bases will not be entered into the Site File. Specific justification and approval of the District Chief are required for data processing and storage outside of the NWIS/WATSTORE systems.

6. The DBM computer specialist will make any necessary additions or corrections to the Advance Station Description (eg. station number, drainage area) and send the final description by electronic mail to the originating FOC or PC, the ADAPS administrator, SWS, and QI.

7. The DBM computer specialist will put a copy of the final Advance Station Description in the directory OPERATIONS>ADV.STA.DESC under a subdirectory for the specific field or project office.

8. The ADAPS DB administrator will use the Advance Station Description to make all necessary entries into the ADAPS system to allow for processing and storage of the data collected at the site.

9. The the Quality Improvement Section will confirm that the new station is in the District's Active List of surface water sites and update any preliminary information as necessary.

\section{Station Identification Number Assignment}

The station identification number is a mandatory entry to the Station Header File, National Water Information System (NWIS) on our PRIME computer, and WATSTORE. Each station for which data are entered in NWIS and WATSTORE must have a single station identification number, unique to that one site. The number should never be assigned to another site, except when the relocation of a site does not significantly change the drainage area of the basin upstream, and streamflow at the new site is equivalent to the old site. Should a station be destroyed or removed from service, its unique number will continue to be associated in the historical files with the data from the deactivated site. In the event of an incorrect entry, corrections will be made by the Data Base Management staff.

All Geological Survey offices are required to develop station identification numbers that conform to the current USGS criteria. A station identification number may be an eight-digit downstream order number or may be composed of latitude, longitude, and a two-digit sequence number (a total of 15 digits).

Downstream Order Number: 
The eight-digit downstream order number must be used for on-stream sites where records are systematically collected on a long-term monitoring basis. Examples of sites that meet these criteria are:

o Regular surface-water stations

o Regular water-quality sites

o Partial-record (surface-water and water-quality stations)

o Spring stations where discharge measurements are made

When a downstream order number is used, the number must contain eight- digits, thus, any preceding or following zeros must be included, such as "01030500". Punctuation such as periods or dashes must not be used in the number.

\section{Latitude-Longitude Sequence Number}

A latitude-longitude sequence number is used primarily for off-stream sites, however, they may be assigned to on-stream sites where there is difficulty in assigning a meaningful downstream order number, or when data are obtained intermittently on a short-term monitoring basis. Examples of the sites that meet these criteria are:
o Wells
o Water-quality grab sample sites
o Surface-water sites at which miscellaneous measurements are made
o Large open-water sites (lake, reservoirs, bays)

If latitude and longitude to the second are used, a two-digit sequence must be appended to differentiate between stations with the same latitude and longitude. The format of a latitude-longitude identifier is:

$\begin{array}{ccc}\text { Latitude } & \text { Longitude } & \text { Sequence number } \\ \text { ddmmss } & \text { dddmmss } & \text { nn }\end{array}$

where $\mathrm{d}=$ degrees, $\mathrm{m}=$ minutes, $\mathrm{s}=$ seconds, $\mathrm{n}=$ number, (01 first site) (02 second site) (03 third site, etc.)

Station Identification Number Assignment:

Station identification number assignments are made only by the DBM Computer Specialists.

\section{Station Descriptions}

Station descriptions (fig. 4) are updated every three years, or when a significant change has occurred. It is the responsibility of the FOC or PC to ensure that station descriptions are updated. Descriptions are reviewed and updated by the responsible field person. The Chief or Lead Technician assures that the description is updated. Station descriptions are reviewed by Quality Improvement staff as part of the record review process. Approximately 10 percent of all station descriptions are reviewed by QI staff each year. Station descriptions are written to include specific types of information in a consistent format (Kennedy, 1983, p. 2) 


\author{
UNITED STATES \\ DEPARTMENT OF THE INTERIOR \\ GEOLOGICAL SURVEY \\ Water Resources Division
}

Date: $9-10-70$

Prepared By: J.R. Jones

Description of Gaging Station on 11446500 AMERICAN RIVER AT FAIR OAKS, CA.

1. Location.--Lat $38^{\circ} 38^{\prime} 08^{\prime \prime}$, long $121^{\circ} 13 ' 36^{\prime \prime}$, in SE $1 / 4$ NE $1 / 4 \mathrm{sec} .17$, T. 9N., R. 7E., on right bank, 2,100 ft downstream from Nimbus Dam, 2.4 miles east of Fair Oaks, 8.1 miles downstream from South Fork.

Datum of gage is $71.53 \mathrm{ft}$ above sea level.

Drainage area: $1,888 \mathrm{mi}^{2}$

Reached as follows: (See road log.)

Cross cableway and gage is $300 \mathrm{ft}$ upstream in 48" CMP house and well.

2. Established.--Nov. 3, 1904. Water stage recorder at present site by USGS Dec. 6, 1957. (After construction of Folsom Dam) All former records were obtained at a site 2-1/4 miles downstream.

3. Gage.--Campbell Scientific CR-10 datalogger. Records at 15-minute intervals.

Outside gage, as follows:

No. $120 \mathrm{ft}$ upstream from well; limits 4.00 to 5.50

$\begin{array}{lllllll}\text { No. } 2 & \text { " } & \text { " } & \text { " } & \text { " } & \text { " } & 5.50 \text { to } 7.74 \mathrm{ft} . \\ \text { No. } 3 & \text { " } & \text { " } & \text { " } & \text { " } & \text { " } & 7.74 \text { to } 11.50 \mathrm{ft} . \\ \text { No. } 4 & \text { " } & \text { " } & \text { " } & \text { " } & \text { " } & 11.50 \text { to } 14.50 \mathrm{ft} . \\ \text { No. } 5 & \text { " } & \text { " } & \text { " } & \text { " } & \text { " } & 14.50 \text { to } 18.80 \mathrm{ft} .\end{array}$

No. 6 on streamward face of well 18.80 to $30.54 \mathrm{ft}$.

Well gage, staff with enamel face; one section; limits $0.50 \mathrm{ft}$ to $30.54 \mathrm{ft}$.

Tape (float) gage, part of recorder.

One $6 \mathrm{ft}$ and three $8 \mathrm{ft}$ well sections and $8 \mathrm{ft}$ house section of 48 " CMP.

Elevation, (gage datum) of bottom of well $0.50 \mathrm{ft}$.

Floor of house $31.8 \mathrm{ft}$, shelf $34.7 \mathrm{ft}$, top of walls, $39.2 \mathrm{ft}$ and top of roof, $40.2 \mathrm{ft}$.

Inside staff gage, at low stage, reads same as outside staff.

Figure 4. Example of gaging station description. 
Center line Elevation

$\underline{\text { Intakes }} \underline{\text { Size }}$ Length $\underline{\text { At Well }}$ Out End Device on End

$\begin{array}{rrrrrl}\text { No. } 1 & 2^{\prime \prime} & 21^{\prime} & 1.36 & 1.36 & \text { cap and plugged in well } \\ 2 & 2 " & 21^{\prime} & 2.36 & 2.36 & \text { cap and plugged in well } \\ 3 & 2^{\prime \prime} & 47^{\prime} & 3.36 & 3.60 & \text { static tube, flushing system } \\ 4 & 2^{\prime \prime} & 42^{\prime} & 4.36 & 4.30 & \text { static tube, flushing system } \\ 5 & 2^{\prime \prime} & 31^{\prime} & 6.36 & 6.40 & \text { static tube, flushing system }\end{array}$

Flushing system: 3 way valves connected to intakes 3 and 4 connected to pump and flushing system.

Observer: None.

Hole in well at $18.8 \mathrm{ft}$ to pump out well, covered with plate and bolted.

Walkway is steel truss with expanded steel floor.

4. Benchmarks.--

R.M. 1 is standard WR brass tablet over a 2" pipe in concrete block $31 \mathrm{ft}$ upstream from well. Elevation 15.81 $\mathrm{ft}$, gage datum. (Levels of 8-22-96).

R.M. 2 is standard WR brass tablet set in concrete footing of walkway to gage well. Elevation $29.62 \mathrm{ft}$, gage datum. (Levels of 8-22-96).

R.M. 3 is standard U.S.G.S. tablet set in concrete $100 \mathrm{ft}$ upstream of RM 1 set in concrete base of sign on right bank. Elevation of $18.68 \mathrm{ft}$, gage datum (levels 8-22-96).

Datum lowered $6.00 \mathrm{ft}$ 7-16-70.

5. Control.--Low water, gravel bar about $900 \mathrm{ft}$ downstream, subject to shift. High water, gravel bar and channel control. Very little brush. Floods will overflow Sailor Bar on right bank, and dredger tailings on left bank, limiting maximum stage at station.

6. Discharge measurements.--Wading measurements location, 800-1000 ft downstream. Wade below gage height of 4.60 only.

High water measurements made from cable, $340 \mathrm{ft}$ below gage.

Span between supports is $500 \mathrm{ft}$.

Supports, on left bank, none on right bank.

Anchors, 7-3/4 cu. yd. concrete anchor on left bank. $10 \mathrm{cu}$. yd concrete sidehill anchor on right bank.

I.P.is near right anchor. A-frame. Cable marked each $5 \mathrm{ft}$.

Flood condition: Measure from Sunrise bridge when GHT is above $15.00 \mathrm{ft}$ or you feel that the cableway is unsafe. Measure next to piers to define channel bottom. There are scour holes about $10 \mathrm{ft}$ deep around piers.

Figure 4. Continued. 


\section{CHANNEL CONDITIONS AT CABLE/BRIDGE}

Bed of stream, gravel and cobbles.

Stream is one channel at all stages.

Greatest depth is

Flow at high stages smooth and evenly distributed.

Horizontal angle corrections, none.

Main channel is straight for 2,100 ft from Nimbus Dam to station; curves to left below control.

Right bank gravel bar to small hardpan shelf at foot of steep bluff.

Left bank dredger tailings. Steep cobble slope to about $22 \mathrm{ft}$ gage height; not likely to overflow as bank is low at control.

Accuracy of discharge measurements should be good.

Auxiliary gage, none.

Weights, needed for h.w. measurement:- 100 pounds for $50,000 \mathrm{ft}^{3} / \mathrm{s}$ or more.

Stored at station: None.

7. Floods.--Maximum flood at Fair Oaks 1904-57, (Prior to construction of Folsom Dam) discharge $180,000 \mathrm{ft}^{3} / \mathrm{s}$ Nov. 21, 1950 (gage height $31.85 \mathrm{ft}$, former site and datum).

$72,100 \mathrm{ft}^{3} / \mathrm{s}$ Dec. 26, 1955 (gage height, $20.35 \mathrm{ft}$, prev. site and datum).

$84,800 \mathrm{ft}^{3} / \mathrm{s}$ Jan. 15, $1980 \quad$ (g.h. $=23.27 \mathrm{ft}$, pres. datum).

$101,000 \mathrm{ft}^{3} / \mathrm{s}$ Feb. 2, $1963 \quad$ (g.h. $=27.44 \mathrm{ft}$, pres. datum).

$115,000 \mathrm{ft}^{3} / \mathrm{s}$ Dec. 23-25, 1964 (g.h. $=27.65 \mathrm{ft}$, pres. datum).

134,000 ft ${ }^{3} / \mathrm{s}$ Feb. 19, 1986 (g.h. $=27.96 \mathrm{ft}$, pres. datum).

8. Point of zero flow.-- $2.8 \mathrm{ft}, 4-16-91$.

9. Winter flow.--No ice.

10. Regulation.--Flow regulated by Folsom Reservoir and Nimbus Dam since Feb. 25, 1955.

11. Diversion.--Diurnal fluctuations from Folsom powerplant re-regulated by Nimbus Reservoir and powerplant. Diversions at Folsom Dam include those for the San Juan Suburban Water District, Natomas Water Company and State of California for Folsom prison. Many diversions upstream from Folsom.

12. Accuracy.--Should be good to excellent.

13. Cooperation.--Station maintained and operated by USGS CBR Federal funds. Cost of relocating station and cableway in 1957 paid by U.S. Bureau of Reclamation in order to have record immediately downstream from Nimbus Dam. Lowering of gage well $6 \mathrm{ft}$ (7-16-70) paid for by U.S.B.R. to maintain record at low flows.

14. Indirect measurement site.--

15. Land ownership.--

16. Purpose of record.--Mainstream primary station.

17. $\underline{\text { Note.-- }}$

18. Quadrangle.--Folsom 1:24000 (1954).

Figure 4. Continued. 


\section{$\underline{\text { ROAD LOG }}$}

\section{DISTANCE FROM INITIAL POINT}

0.0

10.0

10.4

10.5

10.9

\section{DISTANCE BETWEEN}

POINTS

From Watt Ave. and Highway 50 proceed east on Highway 50. 10.0

Take Hazel Ave. exit. Turn left at signal (Hazel Ave.) cross over freeway.*

.4

Turn left at next signal. (Nimbus Road).

.1

Go straight to Fish and Game Headquarters.

.14

Turn right and go past headquarters. Go through first gate on left after passing buildings. turn right immediately and follow around to the cableway.

* To walk to the gage on the right bank, take Hazel to Winding Way, go west (downstream) to Illinois, turn left (south) and proceed to Sailor Bar park. Walk upstream along trail to gage. At flows above 100,000 cfs, trail is unsafe and gage should be approached with EXTREME care.

\section{A. J. Oldtimer 4-17-91}

Figure 4. Continued 


\section{Direct Measurements}

Direct measurements of discharge are made with any one of a number of methods approved by WRD. The most common is the current-meter method.

A current-meter measurement is the summation of the products of the subsection areas of the stream cross section and their respective average velocities (Rantz and others, 1982, p. 80). Procedures used for current-meter measurements are described by Rantz and others, 1982, p. 139; Carter and Davidian, 1968, p. 7; and Buchanan and Somers, 1969, p. 1.

When personnel make measurements of stream discharge, attempts are made to minimize errors. Sources of errors are identified by Sauer and Meyer, 1992. These include random errors such as depth errors associated with soft, uneven, or mobile streambeds, or uncertainties in mean velocity associated with vertical-velocity distribution errors and pulsation errors. These errors also include systematic errors, or bias, associated with improperly calibrated equipment or the improper use of such equipment. To minimize systematic errors field trips should be rotated to different personnel every three years or so, and annually each field trip is performed by someone other than the person who usually makes the trip.

Exchange of current meters among field personnel is expected for each trip or on a specified, regular basis. The idea is to eliminate the possibility of one group of station records being biased by a meter that deviated from the standard meter rating. The exchange has an additional advantage in that it may raise the general level of meter maintenance. The Field Office or Project Chief should assign a specific technician to manage the exchange of meters. A chronological log of meter maintenance and exchange is expected.

District policies related to the measurement of discharge by use of the current-meter method, in accordance with WRD policies, include the following.

Depth criteria for meter selection.--District personnel select the type of current meter to be used for each discharge measurement on the basis of criteria provided by the OSW (written commun., 1995). Meters are used with caution when a measurement must be made in conditions outside of the ranges of the method provided by OSW. Any deviation from those criteria is noted and the measurement accuracy is downgraded accordingly.

\section{Meter Use}

The criteria for meter selection for wading measurements is well documented by Buchanan and Somers (1969) and Rantz and others (1982). These references are a little vague, however, in suggesting meter settings in shallow depths below the depths recommended for the meter. The following is an attempt to clarify and expand on instructions found in Rantz and others (1982).

Depth limits as specified by Surface Water Branch Memo 85.07

Price AA meter, FROM a minimum depth of $1.5 \mathrm{ft}$ to you name it.

Pygmy meter, FROM a minimum depth of $0.5 \mathrm{ft}$ to $1.5 \mathrm{ft}^{*}$, greater than $1.5 \mathrm{ft}$, use the $.2 / .8$ method.

* "Meter may be used in depths as low as $0.3 \mathrm{ft}$ (absolute minimum) by using the 0.6-depth method. It should be recognized, however, that there is an unknown under-registration error when the meter is used in depths less than $0.75 \mathrm{ft}$."

"Meters should be used with caution outside these ranges. Any deviation from these recommendations should be noted, and the measurement accuracy downgraded accordingly." 
For measurements where the majority of depths will be between $1.5 \mathrm{ft}$ and $2.5 \mathrm{ft}$, use the standard AA meter and 0.6 depth settings. If some of the depths are less than $1.5 \mathrm{ft}$, do not change to a pygmy meter, but continue to use the AA meter, and continue to use the 0.6 depth setting to a water depth of $1.2 \mathrm{ft}$. For depths less than $1.2 \mathrm{ft}$, still use the 0.6 depth setting. There will be some error, but it is considered negligible since the total number of verticals with depths less than $1.2 \mathrm{ft}$ should be relatively small. Do not use the so-called 0.5 depth method.

When the majority of depths in a measuring section are between $0.3 \mathrm{ft}$ and $1.5 \mathrm{ft}$, and velocities are between $0.2 \mathrm{ft} / \mathrm{s}$ and $2.5 \mathrm{ft} / \mathrm{s}$, the pygmy meter should be used with 0.6 depth settings. As Rantz points out, the 0.6 method places the pygmy closer to the streambed than $0.3 \mathrm{ft}$. The 0.6 method is still recommended at these shallow depths; do not use the 0.5 method. To quote Rantz, "From a practical standpoint, however, when it is necessary to measure velocities where water depths are as shallow as $0.3 \mathrm{ft}$, the 0.6 -depth method is used. It is recognized, however, that the results obtained in the situation are only approximate values that underestimate the true velocity. Efforts made to date to define shallow-depth coefficients for natural streams have been unsuccessful." (There is minor under-registration error at $0.75 \mathrm{ft}$, with up to 5 percent error at $0.30 \mathrm{ft}$, due to boundary effects.)

If a minor number of sections have depths less than $0.3 \mathrm{ft}$, continue to use the 0.6 method as long as the meter cups are covered with water.

If 25 percent of the verticals are equal to or less than $0.3 \mathrm{ft}$, the section should not be used for a meter measurement. Try to narrow and/or deepen the section, keeping in mind the velocity and number of sections requirements. If this is not practical, consider using a flume, a portable weir plate, making a volumetric measurement, or timing floats.

Point-of-zero-flow measurements are to be made by field personnel for all wading measurements if it is safe to do so. PZF is not required on a regular basis in canals or concrete-lined floodways.

The individual responsible for ensuring that District personnel use appropriate equipment and procedures during periods of low flow is the FOC or PC. Determination that appropriate procedures are used for data-collection activities during low-flow conditions is accomplished by review such as when surfacewater records are reviewed by the FOC, PC, Surface-Water Specialist, or QI Staff. The FOC, PC, Operations Chief, or Surface Water Specialist is responsible for providing answers to questions from District personnel pertaining to data-collection during periods of low flow. 


\section{Measurement Rating Standardization}

All personnel should be aware that a measurement rating DOES NOT imply a rating of the work done to obtain the measurement. Measurement conditions and methods used are to be rated, not performance.

Assumptions:

Essentially ideal conditions, with exceptions noted.

1. Meters are in good condition.

2. The cross section is in a reasonably straight reach.

3. Flow is uniform, no eddies, slack water, or turbulence.

4. Streambed is uniform and free of numerous boulders or vegetation.

5. Measurement section is near the control.

If conditions are less than ideal, measurements should be down-rated.

If a STD AA meter is used under the following conditions, the measurement is considered to be poor.

If mean depth is less than $1.0 \mathrm{ft}$ (Pygmy meter should be used).

If mean velocity is $0.2 \mathrm{ft} / \mathrm{s}$ or less.

If any two verticals have more than a combined total of 20 percent of flow.

If a Pygmy meter is used under the following conditions, the measurement is poor.

If mean depth is less than $0.30 \mathrm{ft}$-- generally not acceptable

If mean velocity is $0.25 \mathrm{ft} / \mathrm{s}$ or less or $>2.5 \mathrm{ft} / \mathrm{s}$.

If any two vertical's have 20 percent or more of flow.

Definition of a good meter measurement

Mean velocity greater than $0.5 \mathrm{ft} / \mathrm{s}$.

Five percent or less of flow in each vertical is preferred, the sum of the 2 largest verticals may not exceed 15 percent of flow.

Mean depth greater than 150 percent of minimum limit of meter

It is recommended that a change of meters not be made during a measurement in response to the occurrence of two or more subsections in a single measurement cross section that exceed the stated ranges of depth and velocity. 


\section{Number of measurement subsections}

The spacing of observation verticals in the measurement section can affect the accuracy of the measurement (Rantz and others, 1982, p. 179). WRD criteria are that observations of depth and velocity be made at a minimum of about 25 verticals, which are normally necessary so that no more than 5 percent of the total flow is measured in any one vertical. Even under the worst conditions the discharge computed for each vertical should not exceed 10 percent of the total discharge (Rantz and others, 1982, p. 140). Exceptions to this policy are allowed in circumstances where accuracy would be sacrificed if this number of verticals were maintained, such as for measurements during rapidly changing stage (Rantz and others, 1982, p. 174). Fewer verticals than are ideal are sometimes used for very narrow streams (about $12 \mathrm{ft}$ wide when an AA meter is used and about $5 \mathrm{ft}$ wide when a pygmy meter is used). Measurement of discharge is essentially a sampling process, and the accuracy of sampling results typically decreases markedly when the number of samples is less than about 25.

\section{Other direct methods of measuring discharge}

It is District policy that WRD and OSW techniques and guidelines are followed when discharge measurements are made with any selected method of measurement. These methods include the moving-boat method, the tracer-dilution method, measurements using float or volumetric techniques, and methods involving portable weirs and flumes (Rantz and others, 1982; Buchanan and Somers, 1969; Kilpatrick and Schneider, 1983; and Lipscomb, 1995).

\section{Computation of mean gage height}

District personnel use procedures for the computation of mean gage height during a discharge measurement presented by Rantz and others (1982, p. 170). Mean gage height is one of the coordinates used in describing the stage-discharge relation at a streamflow-gaging site.

\section{Check Measurements}

The purpose of this policy is to affirm the importance of making check measurements, and to present guidelines on when and how to make check measurements.

Verification of measurements that deviate from an established rating, particularly the high and low portions of the rating, is important. An outlying measurement that is not verified by following measurements creates doubts that are not easily resolved, particularly if the person that made the measurement is relatively inexperienced. A good measurement could be disregarded or a poor measurement given full weight, if a check measurement is not available.

The general policy has been to require a check measurement whenever the measurement plotted more than 5 percent from the established rating, or about 5 percent from a newly established shift curve. This is a reasonable policy, provided the station has a fairly stable control, and measuring conditions are good. If measuring conditions are poor, a more liberal policy is warranted, and the FOC or PC should specify what percent difference from the rating is acceptable for the particular station. For stations with sand channels and no natural or man-made control, the guidelines for check measurements must be very flexible, and will again have to be spelled out by the FOC familiar with the station and rating. In any case, a complete description of the control conditions during the measurement(s) is an absolute requirement. An obvious control change may make a check measurement much less desirable than a follow-up measurement a day or more later at a different stage. 
When making a check measurement, the meter and stopwatch should be changed and another measuring section should be used. If the measuring section is limited to a cableway or bridge, then vary the location of the verticals within the section (Rantz and others, 1982, p. 346).

Corrections for storage.--Corrections for storage applied to measured discharges for the purpose of defining stage-discharge relations are those discussed by Rantz and others (1982, p. 177) and in OSW memorandum 92.09 .

Questions.--Personnel who have questions concerning the appropriate procedures for making stage and discharge measurements should ask a lead technician, FOC, QI staff, or Surface Water Specialist. Communication among and between all levels of staff members is encouraged.

\section{Field Notes}

Thorough documentation of field observations and data-collection activities performed by field personnel is a necessary component of surface-water data-collection and analysis. To ensure that clear, thorough, and systematic notations are made during field observations, discharge measurements are recorded by field personnel on standard USGS discharge-measurement notes. Original observations, once written on the note sheet, are not erased. Original data are corrected by crossing the value out then writing the correct value. Some examples of original data on a discharge-measurement note sheet include gage readings, depth, revolutions and time for velocity observations, and section stationing. Examples of information on a discharge-measurement note sheet that is derived from original data, but not in itself original data, include the total discharge on the front sheet, mean gage height, and others. Derived data can be erased for the purpose of correction.

All discharge measurements are to be calculated in their entirety before field personnel leave the field site, unless emergency evacuation is required for reasons of safety. Information expected to be included by field personnel on the measurement note sheet should satisfy the following guidelines.

\section{Discharge Measurement Note Guidelines}

The following are instructions for filling out Discharge Measurement Notes Form 9-275-F (Rev. 10-81). These detailed instructions are provided to improve and assure consistency in information. It is expected that complete and thorough notes will improve efficiency when working records.

Meas. No.---Number measurements consecutively. Number measurements even if they are not used or are only field estimates. Indirect measurements should also be numbered.

Comp. by---Initials of person computing measurement.

Sta. No.---Must always be included.

Checked by---Initials of person checking measurement. Should not be same person who computed measurement. Applies only to measurements made by personnel with less than a year of experience.

Line for stream name---Identify stream by name that is on the station description.

Date---Enter month, day, year.

Party---List first initial and last name of person making measurement followed by $(\mathrm{m})$ and then name of person servicing gage followed by $(\mathrm{g})$. 
Width---Area---Vel---If measurement is all one channel, list properly rounded values with velocity computed from area and discharge shown on front sheet. If more than one channel for a low-flow wading measurement, do not list combined values, simply note the number of channels. On high-flow measurements, list overflow channels separately if appropriate.

G.H.---List the mean gage height from the Correct M.G.H. box under gage readings. If debris were removed from control, record both before and after gage heights. An * can be used to footnote further explanation if needed.

Disch---List total discharge over control section. Use a properly rounded value. Example of proper rounding are $0.87,3.05,14.2,108,1090,43,500 \mathrm{cfs}$.

Method---Proper entries are .6, .2/.8, vol., est., flume. Other methods can be explained under remarks.

No. secs---Count and record total number of velocity readings taken that are not zero.

G.H. change---Actual change in gage height from time measurement began until measurement ended. May need to be determined from plot on back of measurement note. Include + or - depending on direction of change.

in___ hrs---Time for measurement to nearest .1 hour. Corresponds to G.H. change time.

Susp.---Enter weight used for cable measurement (50c, 75c, 100c, etc.) or rod if used.

Method coef---Usually 1.0. Refer to WSP 2175 (Rantz and others, 1982) for proper techniques to be used.

Hor. Angle coef---If all flow is normal to the cross section, enter 1.0. If direction of flow varies, enter "varies" or "noted". If flow angle is constant, enter coefficient used.

Susp coef---Enter 1.0 unless explained under remarks.

Meter No.---Enter number stamped on yoke so that performance of individual meter may be tracked.

Type of meter.---Either AA, Pyg, OM or flume.

Date rated.---Enter "std" if standard table is used.

Tag checked.---Measure and record here the spacing of any tags set for high-water measurement. Tag spacing is usually referenced to the center-line of the meter cups with tension on the cable. Check spacing before and after each measurement.

Meter ft. above---Enter distance from bottom of weight to center-line of meter cups. Use 0.55 or 0.60 whichever is closest, 0.90 or 1.0 whichever is correct. Distance will change with weight used, so measure to eliminate later doubts. 
Spin before meas after ---Document satisfactory condition of meter by noting OK. Before each measurement, inspect meter for dents and/or fouled pivot, and spin cups to be sure that cups do not wobble excessively and that they stop slowly. Enter a timed spin test on the Field Office meter log at about monthly intervals. The FOC or PC is responsible for seeing that all meters are in condition to make accurate measurements and the procedures that the FOC has implemented will be followed. Overall condition of meter should be described on meter log at time of "monthly" spin test.

Meas plots---Leave blank if control is very unstable. Enter percent plus or minus to the current rating if control is stable. All measurements should be plotted on field curves in order to evaluate trends and determine need for check measurements.

Levels obtained---Enter yes if levels were run, leave blank otherwise.

\section{GAGE READINGS:}

Time---List time of first outside gage reading made before entering gage.

List time for first inside reading of recorders, tapes, and dials.

List time for resetting of recorders.

List start and finish times for measurement.

List time of final gage readings. Be sure to read outside gage.

List any other times needed to determine mean gage height of Meas.

Blank column---To be used for actual reading of inside staff in stilling well or any other reading not having its own labeled column. Column should be labeled "Well" if well reading is made.

Inside---For stilling well, show tape reading; pressure system, show dial reading, or readout.

ADR--- Digital reading from dial or punch. Dial and punch readings should be the same, explain if different or reset.

BDR or similar recorder--- Record observed value.

Graphic---Pen reading.

Outside---Read on arrival, and before leaving. Remember this is the reference gage for a manometer, and indicates if there is communication to a stilling well. Read again if there is a change due to purging or flushing.

Weighted M.G.H.---Determined from gage height change during measurement.

G.H. Correction---List if correction needed.

Correct M.G.H.---Gage height for measurement. Should be initialed by person who checks measurement against gage heights stored in ADAPS, to indicate agreement with final determination.

Check bar found---For use with wire-weight gage. List elevation of check bar once per visit. 
Wading, cable, etc.---Indicate type of measurement and location of measurement section relative to gage.

Measurement rated---Circle or underline one rating only. No combined rating such as "fair to poor" should be used.

Flow---Describe flow conditions (smooth, turbulent, eddies, standing waves, dunes etc.)

Cross section---Describe measurement section (sand, cobbles, boulders, bedrock concrete, etc.)

Control---Describe what control is composed of, section or channel, presence of drift, vegetation, any change since previous visit, any change made currently that might change gage height at this stage or later.

Gage operating---OK or yes, if operating properly; if not, say no and explain in REMARKS. Weather---Describe any inclement type such as high wind or rain plus any other as desired. Intake/orifice cleaned---Yes or no. If gage height changed due to cleaning, describe under remarks. Air____ Water___---List water temperatures to nearest half degree Celsius. Air temperature can be left blank.

Record removed---Yes or no.

Extreme indicator---List max and min DPI readings. Show gage height before applying constants and constants on either chart, digital leader, or measurement.

Manometer Tank____Feed---List pressures from gages on tank.

Bbl rate---Count and list number of bubbles in one minute.

CSG checked___Stick reading---List readings for crest-stage gages as needed to describe which gage read and what reading was. Stick reading should be noted and then added to pin elevation to obtain final csg reading. Indicate if marks are good or fair or not reliable. Be sure to clean marks off stick and recork csg. If none, enter NONE.

Observer---Usually blank.

HWM---Record marks in stilling well (check silt level at same time) and then wipe off inside staff and/or well near staff so that next peak will leave new marks. Use hand or string level to record any outside marks near gage for peak since last visit. Check against recorded peak and determine reason for any difference, if possible. If any record was lost since last visit, observe channel to determine recent flow range. If no marks can be found near gage, flag or otherwise mark HWMs upstream and downstream to be leveled to later. If no marks or indications of high flow are found, record NONE

Remarks---Any comments that may relate to record computation or general safety.

G.H. of zero flow---PZF should be recorded each time it can be accurately and safely determined at most natural sites. PZFs on streams that go dry are especially important. 


\section{Flume measurements}

When making a flume measurement, be sure to record the identification number of the HIF flume in the measurements notes. The care of flumes is very important, as dents and misalignment can severely affect the flume rating. For proper use of flumes, refer to Kilpatrick and Schneider (1983). These portable devices are applied according to methods described by Buchanan and Somers (1969, p. 57) and Rantz and others (1982, p. 263).

\section{Measurement Checking}

1. Each trained person making discharge measurements is solely responsible for completely and accurately filling out the 'front sheet', and the computational accuracy of the measurement.

2. Each person immediately upon completion of a measurement computation is expected to:

a. Scan the measurement for obvious errors in velocity, depth, partial areas, partial discharges.

b. Scan for misplaced decimal points.

c. Check the sum of partial widths against total width.

d. Recompute the sum of partial areas and discharges.

3. For personnel with less than 6 months experience, a 100 percent review of computational accuracy, and 'front sheet' data will be made. After 6 months, partial checking should be done by a lead technician, FOC, or PC until competency is demonstrated.

4. For personnel that have demonstrated competency to the satisfaction of their supervisor, routine checking of their work is not required. Spot checks, on a random basis, are recommended once or twice per year.

5. If a measurement, when compared to the rating, is more than 10 percent off the existing trend, a check of that measurement is recommended. This does not apply to channels that normally shift a large amount. For those channels, each gage should have limits for percent off, agreed to by the hydrographer and supervisor (based on personal knowledge of the site), that would require a complete review.

6. To improve consistency, and increase information available for working records, the following is recommended, but is not required. Objective criteria for evaluating measurement notes have been established. Those criteria may be used (by each hydrographer) to evaluate a sample consisting of three randomly selected measurement notes from each field trip. The mean and range of the three should be plotted on a process control chart. Example charts will be provided on request, as will a District mean, and upper and lower control limits (UCL, LCL). Any plotted point(s) that fall below the LCL should be considered "out of control", due to a special cause, and that cause should be immediately identified and corrected.

Usage of this method would identify problems due to special causes, and reduce variability in results. A control chart provides instant analysis of how well each person is doing the task of filling out notes. The control chart acts as a feedback loop to each individual. If used correctly, reductions in missing data, and overall improvement of results are expected. The method is expected to improve 
consistency (reduce variation) and increase information available for working annual gaging station records. An incremental increase in efficiency during record computation is expected.

All miscellaneous notes are expected to include initials and last name of field-party members, date, time associated with observations, and purpose of the site visit.

Deficiencies found in the content, accuracy, clarity, or thoroughness of field notes are identified and communicated to the field technician by written or oral means. The deficiencies are remedied by providing specific instructions from the lead technician, FOC, or PC to individuals who fail to record notations that meet USGS and District standards.

\section{Acceptable Equipment}

Equipment used by the California District for the measurement of surface-water discharge has been found acceptable by the WRD through use and testing. An array of acceptable equipment for measuring discharge includes current meters, timers, wading rods, bridge cranes, tag lines, and others (Rantz and others, 1982, p. 82; and Smoot and Novak, 1968). Although an official list of acceptable equipment is not available, Buchanan and Somers (1969), Carter and Davidian (1968), and Edwards and Glysson (1988) discuss the equipment used by the Geological Survey.

The meters most commonly used by District personnel for measuring surface-water discharge are the Price AA current meter and the Price pygmy current meter. Methods followed by District personnel for inspecting, repairing, and cleaning these meters are described by Smoot and Novak (1968, p. 9), Rantz and others (1982, p. 93), and Buchanan and Somers (1969, p. 7).

The ultimate responsibility for the good condition and accuracy of a current meter rests with the field person who uses it (OSW memorandum 89.07). A timed spin test made a few minutes before a measurement does not ensure that the meter will not become damaged or fouled during the measurement. Field personnel must assess apparent changes in velocity or visually inspect the meter periodically during the measurement to ensure that the meter continues to remain in proper operating condition.

Spin tests.--It is District policy that spin tests are required prior to each field trip. Spin-test results are documented in a log that is maintained for each instrument. The log is located in the respective field or project office. This log is part of the archival data of WRD (OSW memorandum 89.07). Repairs are made to meters when deficiencies are identified through the spin test or inspection. Review of this log by a lead technician is made annually. If deficiencies are observed during this review of the log, the field person responsible is informed and the problem is corrected immediately.

\section{Alternative Equipment}

New conditions and the development of new technology sometimes involve the collection of surfacewater data with alternative equipment that has not been fully accepted by WRD. To demonstrate the quality of surface-water data collected with alternative equipment, thorough documentation of procedures and observations must be maintained.

It is the responsibility of the FOC or PC to ensure that alternative equipment is utilized correctly and that documentation is comprehensive and is stored correctly. 


\section{Indirect Measurements}

In many situations, especially during floods, it is impossible or impractical to measure peak discharges by means of a current meter. There may not be sufficient warning for personnel to reach the site to make a direct measurement, or physical access to the site during the event may not be feasible.

When major floods occur, one immediate need is field reconnaissance of prospective sites for indirect measurements. To reduce the time requirement before field work on indirect measurements can begin and to try to simplify decisions regarding selection of $n$-values, the following policy is instituted.

Responsibility for implementation of this instruction is assigned to the FOC or PC. These instructions apply to all appropriate gaging stations, but initially, are for all new continuous recording gaging stations and new peak flow stations. At these stations the following should be obtained:

1. Select the best indirect measurement site in the vicinity of the gage if a usable site can be found. Critical depth, flow over dams, culverts, contracted openings, and slope-area sites should be investigated. The required geometry should be surveyed. Cross sections for indirects other than slope areas should be selected and referenced with steel rods or pipe, or referenced by distance and azimuth to local permanent structures. A permanent RM should be located at the beginning of the slope area reach. Stereo photographs should be taken and initial estimates of the Manning's ' $n$ ' roughness coefficient determined (Barnes, 1967). After the first significant high-water measurement, or well-defined peak, reaches should be flagged, cross sections surveyed and water- surface profiles obtained, and the program NCALC (R.D. Jarrett, written commun., 1985) could be used to obtain verified n-values.

2. Obtain a cross section at each gage-control section, with monumented end points.

3. Establish cable gages if cableways are more than 200 yards from the gages.

4. Perform a step-backwater computation at each gage, if practical. This technique will help define the rating curve shape and reduce the probability of later revisions. At those offices with little experience using the step-backwater technique, consult with operation's supervisors, QI staff, or Surface Water Specialist before field work is done.

5. Include the location of indirect measurement sites and road logs to the sites in the station descriptions.

Exceptions to this policy are canals, ditches, and low-flow-only sites, and sites that have a high potential for rating definition throughout the range in stage by current-meter measurements. Existing gaging stations with rating extensions greater than one-half log cycle come under the above policy unless the control is exceptionally stable and the rating curve very well defined.

A peak discharge determined by indirect methods is in many situations the best available means of defining the upper portions of the stage-discharge relation at a site. Because extrapolation of a stage-discharge relation, or rating, beyond twice the measured discharge at a gaging station is undesirable and may be unreliable, discharge measurements made by indirect methods during periods of high flows are important forms of data (Rantz and others, 1982, p. 334).

The District follows data-collection and computation procedures presented by Benson and Dalrymple (1967). That report includes policies and procedures related to site selection, field survey, identification of high-water marks, the selection of roughness coefficients, computations, and the written summary. The District also follows procedures for measurement of peak discharge by indirect methods presented by Rantz and others (1982, p. 273). 
In addition to the general procedures presented by Benson and Dalrymple (1967), the District follows guidelines presented in other reports that describe specific types of indirect measurements suited to specific types of flow conditions. The slope-area method is described by Barnes (1967) and Dalrymple and Benson (1967). The USGS applies the Manning equation in application of the slope-area method. Procedures for selecting the roughness coefficient are described by Arcement and Schneider (1989). The computer-based tool, program C374, available to assist in computations of peak discharge with the slope-area method, is discussed in OSW memorandum 83.07. Procedures for the determination of peak discharge through culverts, based on a classification system that delineates six types of flow, are described by Bodhaine (1982). The computer-based tool, program A526, available to assist in computations of peak discharge at culverts, is discussed in OSW memorandum 83.07. At sites where open-channel width contractions occur, such as flow through a bridge structure, peak discharge can be measured with methods described by Matthai (1967) and with the Water-Surface Profile Computation model (WSPRO) (Shearman, 1990). Debris-flow conditions, which are most common in small mountainous basins, are discussed in OSW memorandum 92.11.

It is the responsibility of a well-trained technician to identify and flag high-water marks. Because the quality and clarity of high-water marks are best soon after a flood, personnel traveling in the field are expected to have available in their field vehicles marking equipment such as nails, spray paint, paint sticks, and survey flagging.

Determinations of water-surface profiles along a stream channel in association with selected discharges are made when studies are performed that involve delineations of flood plains or when extensions are made to stage-discharge relations at streamflow sites. District personnel are expected to follow the procedures associated with step-backwater methods described by Davidian (1984). The computer-based tool used for assisting in the computations of water-surface profiles with step-backwater methods, WSPRO, is discussed in OSW memorandum 87.05.

General guidelines that are followed by the District when making indirect measurements include those discussed in OSW memorandum 92.10 and by Shearman (1990). Violation of any one of the general guidelines does not necessarily invalidate an indirect measurement (OSW memorandum 92.10). If the watersurface profile or computations indicate that a hydraulic jump was likely in the reach, the measurement is considered invalid. If spread is greater than 25 percent, and other internal indicators are poor, the measurement may be considered invalid. If there are too few high-water marks to correctly identify a profile, the computation is invalid. If the water-surface slope exceeds 5 percent, the measurement may be invalid. If field evidence indicates significant scour, or that a debris flow occurred, the measurement may be considered invalid.

Determining when and where indirect measurements are made is the responsibility of LT, FOC, or PC. For this District, it is a general rule that indirect measurements are made at sites when peak flow at a site is estimated to be at least twice the discharge of the greatest measured flow. Indirect measurements are often required for every significant peak on sand channel streams.

After each indirect measurement is computed, the graphs, field notes and data, plotted profiles, maps, calculations or computer output, and written analysis associated with the measurement are checked by a lead technician, FOC, or PC. The information is organized in a single labeled folder and is then stored in the permanent records of the gage. Long-term storage of each indirect-measurement package is provided in the Quality Improvement Section files. (Many older measurement files still reside in the National Archives). All measurements stored in the archives OR district office files must have an entry in the archive index data base. 
The responsibility for ensuring that indirect measurements are performed correctly is held by the chief of party. A review of procedures and documentation will be performed by the Surface Water Specialist or QI staff for all indirect measurements of discharge. All aspects of an indirect measurement are reviewed, including:

Reconnaissance, field procedures, notes, sketches.

Photographs, Computations, Summary

If deficiencies are found during the review, actions taken to remedy the situations include:

1. Measurement returned to Chief of Party for more field work, correction, or recomputation.

2. Recomputation and analysis as needed.

3. The responsible FOC or PC is kept informed of the quality of field and computational work

Difficult-to-assess indirects are reviewed by the Regional Surface Water Specialist. The District Surface Water Specialist is responsible for ensuring that deficiencies identified by the outside party are corrected.

The California District criteria for selecting peaks above base for publishing in the Annual Data Report were set forth in a District memo dated October 23, 1981, and are reprinted below: "The term, "Peaks Above Base," has not been adequately defined to fit some streamflow patterns. This is particularly true in the case of arid regions such as southern California. Peaks above base (PAB) are used by a few groups, principally the U.S. Army Corps of Engineers and U.S. Department of Agriculture's Soil Conservation Service, in determining the frequency of flood damage. For this purpose, the criteria should define separate, independent events. Obviously, a series of peaks occurring, for example, on February 14, 16, 18, 19, and 21 do not constitute independent events even though they are independent by the criteria given in (preparation guide of Water Resources Data Reports by Novak, 1985). We are directed to select a base for $\mathrm{PAB}$ that will be exceeded on the average three times a year. The station that experienced the 5 peaks in 8 days for February as noted above has 31 years of record. During the 31 years, there were 94 PAB and average very close to three annually. However, during four of the 31 years, 38 of these peaks occurred. Twelve PAB came in 1980 alone.

Therefore, do not publish a peak unless the discharge of the trough between it and the adjacent higher peak goes down to 50 percent or less of the lower peak, and remains that low for at least 48 hours.

(Example: if two consecutive PAB are 2,000 $\mathrm{ft}^{3} / \mathrm{s}$ and $1,500 \mathrm{ft}^{3} / \mathrm{s}$, they are independent only if there are 48 hours of flow less than $750 \mathrm{ft}^{3} / \mathrm{s}$, between the two)."

\section{Crest-Stage Gages}

Crest-stage gages are used as tools throughout the WRD for determining peak stages at otherwise ungaged sites, confirming peak stages at selected sites where recording gages are located, confirming peak stages where manometers or pressure transducers are used, and determining peak stages along selected stream reaches or other locations, such as upstream and downstream from bridges and culverts. The OSW requires quality-assurance procedures comparable to those used at continuous-record stations for the operation of crest-stage gages and for the computation of annual peaks at crest-stage gages (OSW memorandum 88.07). 
The operation of crest-stage gages is part of this District's surface-water program. Procedures followed by this District in the operation of crest-stage gages are presented by Rantz and others (1982, p. 9, 77, 78). One or more gages are maintained at each selected site where peak water-surface elevations are required on a stream. Upstream and downstream gages are maintained at culverts or other structures where watersurface elevations are required to compute flow through the structure and to establish the resulting type of flow.

At some sites, a crest-stage gage may not be practical due to high velocities. In this case, installation of a strip of chicken wire or some similar debris-catching device may be an acceptable substitute for a conventional crest-stage gage.

Except at sites where crest-stage gages are used only to confirm or determine peak stages, stage-discharge relations are developed in association with the gage based on direct or indirect high-water measurements. Direct or indirect measurements are obtained when possible, to verify or adjust the rating. Levels are run to the gage every 3 years, or as soon as possible after significant changes in the gage because of damage to the gage, reconstruction, or other events. When extremely high peaks occur, an outside highwater mark to confirm the gage reading is found when possible, is described on the note sheet, and is flagged by a durable indicator so that the elevation of the high-water mark can be determined the next time levels are run.

Field observations are written on standard crest-stage gage note sheets. All field notes are required to include: initials and last name of field person, date, time of observation, gage height(s), outside high-water marks, and condition of control

The responsibility for ensuring that correct data-collection procedures are used by personnel is held by the FOC, PC, and Operations Chief. This responsibility is carried out by examining field note sheets. When a deficiency in data-collection activities is identified, the problem is remedied by further training, provided by the FOC, PC, or Surface Water Specialist.

\section{Peak Flow Files}

The responsibility of maintaining the accuracy of the peak-flow data files, including computer database files, lies within the District (OSW memorandum 92.10). It is the responsibility of the FOC or PC to ensure that appropriate indirect-measurement results are entered into the peak-flow files. It is the responsibility of FOC or PC to ensure that the peak-flow files are correct. The Surface Water Specialist or Surface Water QI staff perform various types of reviews of peak file data, including but not limited to: bounds.

1. Graphical analysis of peak discharge versus drainage area, by storm, within hydrologic regional

2. Graphical analysis of maximum peak discharge versus drainage area, within regional hydrologic bounds or for the entire district.

For further discussion on the update and review of the peak-flow files, refer to the "Data-base Management" section in this QA Plan.

The peak flow file is a National Water Information System (NWIS) data base containing instantaneous maximum stream discharge data and associated gage heights. It contains one or more peaks for each station per year. The file is organized by agency, station, and water year. 
To maintain uniformity of peak-flow data entered into NWIS, the following set of basic procedures have been established for use:

1. Each year the peaks for California District streamflow stations will be entered into a computer file and transmitted to the Data Base Management (DBM) Computer Specialist for verification and further processing.

2. To avoid missed peaks, primary computations or peak discharge forms should be used to determine all peaks above base. As a cross check, the DBM will check input files against the annual data report.

3. The detailed format for entering peaks is shown in WATSTORE, Vol. 4, Chapter I, "INSTRUCTIONS FOR PEAK FLOW FILE." However, for California District purposes, some of the codes for qualifying discharge have been further clarified and are shown below:

Code 1: Discharge is a maximum daily mean -- Applies only if there is no instantaneous peak available. Should be applied to any daily value in the peak file.

Code 2: Discharge is an estimate -- Should be used for any peak that is estimated by methods such as hydrographic comparison, flood routing, or drainage area relations. Standard indirect methods are considered to be measurements.

Code 3: Discharge affected by dam failure -- Should be applied whenever a significant portion of the flow is affected by the failure. Fifteen percent would be a significant amount.

Code 5: Discharge affected, but to an unknown degree, by regulation or diversion -- If total regulation and storage in the basin are undetermined and/or if total diversion into or out of the basin is ungaged, use this code.

Code 6: Discharge affected by regulation or diversion -- Use this code if the total usable storage capacity, in acre-ft, divided by drainage area, in square miles, is greater than 103 . This should also be used if diversions exceed 10 percent of peak flow.

Code 9: Discharge due to snowmelt, hurricane, ice jam or debris dam breakup, or debris flow -- If a natural event, use Code 9; if an artificial structure fails, use Code 3.

Generally, the field offices will be coding peaks for one water year at a time. However, in case of additions, revisions, or corrections to previous years in the Peak File, the FOC or PC will be responsible for coding such data. In these cases, an explanatory note should be sent along with the data so that the dates of peaks and the water year are clearly identified.

As explained in WATSTORE VOL. 4, the " 2 and 3 cards" (the ENT and maximum peak of year cards) are essential for entering data for each station, and the "4 card" (partial or secondary peak card) is optional. Only ONE " 2 card" is necessary per station EVEN IF coding more than one water year. 
When the base flow for peaks is newly determined, revised, or dropped, it must be given a discharge qualification code of "D" and the DBM Computer Specialist must be notified in order to reflect the change in the Site File. Failure to do so may result in the secondary (partial) peaks being dropped from the Peak File.

Sample coding sheets and an updated checklist were issued to each office as aids for coding the Peak File. These items should be reviewed each year and used to help eliminate the many different errors that occur. Coding errors such as incorrect dates will not only affect the current water year but could alter previous year's peaks as well.

Policies and procedures for computation of peak discharges at crest-stage gages and associated documentation are presented in this report in the section entitled "Processing and Analysis of Stage and Streamflow Data."

\section{Artificial Controls}

Artificial controls, including broad-crested weirs, thin-plate weirs, and flumes, are built in stream channels for the purpose of simplifying the procedure of obtaining accurate records of discharge (Rantz and others, 1982, p. 12). Such structures serve to stabilize and constrict the channel at a section, reducing the variability of the stage-discharge relation.

Artificial controls are used at some gaging stations maintained by this District. In situations where artificial controls are installed as permanent structures, it is District policy that stage-discharge relations are determined by making current-meter measurements throughout the range of stage, or by relying on indirect measurements or the design rating when current-meter measurements cannot be made (Rantz and others, 1982, p. 17, and Kilpatrick and Schneider, 1983, p. 40).

Ensuring the correct design and installation of artificial controls for this District is the responsibility of the FOC or PC. When installing an artificial control, District personnel take into account the criteria for selecting the various types of controls, principles governing their design, and the attributes considered to be desirable in such structures (Carter and Davidian, 1968, p. 3; Rantz and others, 1982, p. 15 and 348; and Kilpatrick and Schneider, 1983, p. 2 and 44).

When field inspections of artificial controls are performed, specific information pertaining to control conditions are written on the field note sheets to assist in analysis of the surface-water data. These notes include noticeable scour or fill of the streambed immediately upstream from the control or significant algae growth on the control or in the approach pool. Any indication of submergence or partial submergence should be noted. Regular maintenance at artificial controls includes repair of damage and removal of debris, and algae. All actions taken that might affect the control are detailed on the note sheet. When problems pertaining to artificial controls are encountered by field personnel, consultation with FOC, PC, Operations Chief, QI staff, or Surface Water Specialist is encouraged. 


\section{Flood Conditions}

Flood conditions present problems that otherwise do not occur on a regular basis. These problems can include difficulties in gaining access to a streamflow gage or measuring site because roads and bridges are flooded, closed, or destroyed. Debris in the streamflow can damage equipment and present dangers to personnel collecting the data. Rapidly changing stage or conditions requiring measurements to be made at locations some distance away from the gage can create problems in associating a gage height to a measured discharge.

The District maintains a flood plan so that high-priority surface-water data associated with flood conditions are collected correctly and in a timely manner. The flood plan describes responsibilities before, during, and after a flood, informational-reporting procedures, and field-activity priorities. The flood plan serves as a central reference for safety considerations, emergency communications, telephone numbers for key District personnel, and codes for accessing streamflow gages equipped with telemetry. The flood plan is maintained as a computer file and is reviewed and updated each year.

It is the responsibility of the Operations Chief to ensure that the flood plan includes all appropriate information, including updated information. A copy of the flood plan is available to all personnel. Each individual that receives a copy keeps it where they desire. It is the responsibility of the FOC or PC to ensure that individuals that receive a copy of the plan are fully versed on its content.

During a flood, coordination of flood activities is performed by the Flood Coordinator. This individual may be the Operations Chief, QI Staff member, or Surface Water Specialist. For personnel that are not already in the field, their first responsibility during flood conditions is to call the FOC, PC or Flood Coordinator before driving to the office. For personnel that are already in the field, their first responsibility during flood conditions is to proceed to make a measurement at the first streamflow site, then call the FOC, PC, or Flood Coordinator. Personnel who arrive at a gaging station to find that a flood has occurred are responsible for making a discharge measurement, then proceeding to find and document high-water marks before calling the FOC or PC.

Following a high-water event, several sources of information may be available at a gaging station to document the peak stage. They are (1) the recorded peak (maximum ADR value), (2) backup A-35 pen trace, (3) DPI peak, (4) HWM in well, (5) CSG peak, and (6) outside HWM's. Generally, these peak figures will differ, and a decision has to be made as to which figure to publish. The policy has been to publish the maximum recorded value as the peak stage, providing the difference between the highest value and the DPI, or A-35 pen trace, or the well HWM, is not greater than 0.05 feet. If the DPI or pen trace is more than 0.05 feet higher than the ADR recorded peak, the DPI or A-35 peak is used. If the DPI or A-35 did not register the peak for some reason, but a good well HWM is more than 0.05 feet higher than the ADR peak, then the well HWM peak is published. The DPI or well HWM are preferred because of the possibility of the peak occurring in the 15-minute interval between values.

These are not hard- and-fast rules; documented surge at some stations may dictate the use of different criteria. If the outside HWM's are approximately 0.5 feet or more higher than the recorded peak, there is a reasonable chance that the difference is due to drawdown, or sluggish intake action and we may want to publish an outside peak as well as a recorded peak. Manometers are known to under-register peaks when there is a heavy surge (Beck and Goodwin, 1970). Even if a well defined, consistent, drawdown condition exists, it is good practice to publish the outside HWM peak if the drawdown is large, especially if the gage is in an urban area. The peak stage may have been observed by local residents who are more interested in stage than in discharge. 
Outside HWM profiles at the gage should be carefully determined. At least one mark upstream and one downstream from a stilling well or an orifice should be surveyed with a hand level. The marks should be on the same bank as the gage, and in the vicinity of the gage. The outside peak gage-height should be picked from a water-surface profile drawn through the plotted HWM's. This should be done after every significant peak.

At bubble gage sites, the question often arises regarding when to use the CSG peak in preference to the recorded peak. Generally speaking, the recorded peak should be used unless the CSG reading is several tenths of a foot higher. No District-wide limiting difference is recommended; this is best established station by station, by personnel familiar with the surge, drawdown, or intake lag that has been observed at each station. CSG's are not stilling wells; they dampen some of the surge and wave action, but generally record a peak that is significantly higher than a manometer would record at the time of the peak. Furthermore, CSGs are seldom located at exactly the same point as the orifice, which is another source of disagreement between the CSG and manometer readings.

Considerable care must be taken in using outside HWM's and CSG readings to determine peak discharges. Plots of ADR readings versus outside HWM's, CSG peaks, and observed outside staff readings are very useful in determining the relationship between various peak values. There may be separate relations between the outside HWM's and the ADR; the CSG and the ADR; and the staff and the ADR; avoid compositing these relations unless the differences are small. Regression curves can be used to estimate missing or incorrect ADR peak values. Manual recomputation of faulty or incompletely recorded flood peaks may be avoided by substituting estimated ADR values based on A-35, DPI, CSG, or outside HWM's into the unit-values file.

District personnel follow policies and procedures stated in a number of publications and memorandums when collecting surface-water data during floods. Techniques for current-meter measurements of flood flow are presented by Rantz and others (1982, p. 159 to 170). Procedures for identifying high-water marks for indirect discharge measurements are presented by Benson and Dalrymple (1967, p. 11). Adjustments applied to make measured flow hydraulically comparable with recorded gage height when discharge measurements are made a distance from the gaging station are presented in OSW memorandum 92.09 and by Buchanan and Somers $(1969$, p. 54). It is the responsibility of all personnel with questions about particular policies or procedures related to flood activities, or who recognize their need for further training in any aspect of flood-data-collection, to address their questions to their supervisor.

Review of District activities related to floods is the responsibility of Operations Chief. This review includes seeing that guidelines and priorities spelled out in the flood plan are followed and that the guidelines appropriately address District requirements for obtaining flood data in a safe and thorough manner. When deficiencies are identified by the reviewer, deficiencies are remedied by oral or written communication provided to the FOC or PC.

\section{Low-Flow Conditions}

Streamflow conditions encountered by District personnel during periods of low flow are typically quite different from those encountered during periods of medium and high flow. Low-flow discharge measurements are made to define or confirm the lower portions of stage-discharge relations for gaging stations, as part of seepage runs to identify channel gains or losses, and to help in the interpretation of other associated data. Additionally, low-flow measurements are made to define the relation between low-flow characteristics in one basin and those of a nearby basin for which more data are available (OSW memorandum 85.17). 
In many situations, low flows are associated with factors that reduce the accuracy of discharge measurements. These factors include algae growth that impedes the free movement of current-meter buckets and larger percentages of the flow moving in the narrow spaces between cobbles. When natural conditions are in the range considered by the field personnel to be undependable, the cross section is physically improved for measurement by removal of debris or large cobbles, construction of dikes to reduce the amount of non-flowing water, or other such efforts (Buchanan and Somers, 1969, p. 39). After modification of the cross section, the flow is allowed to stabilize before the discharge measurement is initiated. Modifications to the channel should be made at locations that will not affect the gage height. If modification changes the gage height, notes are to be made on the note sheet that detail what modifications were made and where.

\section{Cold-Weather Conditions}

Surface-water activities in this District include making streamflow-discharge measurements during cold weather conditions. Cold temperatures, wind, snow, and ice can create difficulties in collecting data. These factors also can create dangers to field personnel. The highest priority in collecting streamflow data during winter periods is employee safety.

For gaging stations where the stream is subject to freezing during the winter, discharge measurements under ice cover and during periods of partial ice cover are useful for analysis and determination of flow throughout winter periods. District personnel are expected to follow procedures for discharge measurements under ice cover presented by Buchanan and Somers (1969, p. 42). This same publication includes procedures for discharge measurements made by wading or discharge measurements from cableways and bridges when debris and ice are in the streamflow. District personnel also follow procedures to collect winter streamflow data as presented by Rantz and others (1982, p. 124). Additionally, guidelines on equipment for measurement of flow under ice are provided in OSW memorandum 84.05.

Presently, OSW views the preferred metering equipment for discharge measurements for slush-free conditions under ice cover to be a type AA current meter built with a Water Survey of Canada (WSC) winter-style yoke with a conventional metal-cup rotor. For conditions where slush ice is present, the OSW views the preferred metering equipment to be the WSC winter-style yoke with a polymer rotor (OSW memorandum 88.18). Although polymer rotors are not allowed (OSW memorandum 90.01) during all other conditions, the superior ability of the polymer rotor to shed slush ice and retard freezing in ice-covered streams is considered to be more important than the turbulent-flow-related inaccuracies associated with the rotor (OSW memorandum 92.04). The OSW also views the regular AA meters with conventional metal-bucket rotors to be acceptable for use in slush-free conditions if cutting the required larger holes through the ice is feasible (OSW memorandum 92.04).

The FOC or PC is responsible for ensuring the correct use of equipment and procedures for surfacewater data-collection activities during periods of winter conditions. This is accomplished by reviewing field notes immediately following winter field trips or reviewing field-note sheets when station records are reviewed annually.

\section{PROCESSING AND ANALYSIS OF STREAMFLOW DATA}

The computation of streamflow records involves the analysis of field observations and field measurements, the determination of stage-discharge relations, adjustment and application of those relations, and systematic documentation of the methods and decisions that were applied. Streamflow records are computed and published for each gaging station annually (Rantz and others, 1982, p. 544). 
This section of the QA Plan includes descriptions of procedures and policies pertaining to the processing and analysis of data associated with the computation of streamflow records. The procedures followed by the California District coincide with those described by Rantz and others (1982) and by Kennedy (1983).

\section{Measurements and Field Notes}

The gage-height information, discharge information, control conditions, and other field observations written by personnel onto the measurement note sheets and other field note sheets form the basis for records computation for each gaging station. Measurements and field notes that contain original data are required to be stored indefinitely (Hubbard, 1992).

Measurements and other field notes for the water year that is currently being computed are filed in the current record folder. Measurements and notes for previous water years are filed in the back files for the gage.

After the measurement data are entered into computer files by use of standard USGS software then a paper printout of that information may be filed.

Original data obtained by direct observation in the field is called "observed data" here; subsequent values derived from the observed data are called "computed data." The distinction between observed data and computed data is that observed data cannot be recovered if lost; computed data can always be recovered from the observed data. Therefore, observed data should never be altered or destroyed.

The same basic principles can be applied to sediment, water quality, and ground water field notes, level and survey notes, and the observations recorded on charts or tapes. (SWBM 69.03)

\section{Measurement Summary List (9-207)}

The ADAPS Discharge Measurement listing will be the official final documentation to accompany the station record and, as such, must be complete and accurate. Print out the full, expanded ADAPS form and file with the final record. A hand-listed form 9-207 may be filled out at the field office chief's discretion, but is not a District requirement.

\section{Guidelines for ADAPS measurement listing}

Detailed instructions for filling out the ADAPS form are contained in the ADAPS users manual, section 7.5. List all measurements and station visits in ADAPS. Also enter, at least, all measurements from the high water 9-207. Use, as the gage height for the measurement, the gage height that would be used for plotting in cases where there is a change during the visit, as only one gage height may be listed. Measurements with multiple channels will have to show the aggregate value for width and area, and an average velocity. Under "REMARKS," explain change of XX.XX caused by resetting to outside reading or clearing of the orifice/intake, say "multiple channels" if appropriate. Also in "REMARKS", list the point of zero flow (PZF) and, if appropriate, that there is "No Flow" at the time of the visit. 
No.--This is measurement number. Number the measurements consecutively in chronological order including all field estimates and indirect measurements. Record observations of no flow, but do not number these as measurements. Append the letter " $E$ " to the number for all field estimates of flow (flows based on field observations or rough measurements of channel geometry). Direct determinations of flow based on standard measurement techniques, however poor, are considered measurements and are listed without an "E". Determinations of peak flow by indirect methods will be classified as measurements or estimates during the process of analysis and review.

Date--Show month and day. Indicate year on first line, and again on the first measurement made in new calendar years.

Made by--If two or more people were involved, show the first initial and last name of person making the measurement first, and the notekeeper second.

Width, area, mean velocity, gage height, discharge--If flow was in more than one channel, for large channels, such as high-flow bypasses, show the total discharge. Low-flow measurements in multiple channels can be shown as aggregate width, area, and average velocity. Statements about the presence of multiple channels in low-flow conditions may be entered under remarks if desired.

Gage Height--If desired, two gage heights, before and after cleaning control, purging, or flushing, may be shown in this column. (Use Remarks in ADAPS.)

Shift adjustment and percent difference--Show the percent difference only if a shift was not used, or if a partial shift was applied.

Method--List the predominant methods. In other words, if you make a $0.2 / 0.8$ depth measurement but take 0.6 depth velocities at a few edge sections, list only $0.2 / 0.8$ as the method. In the upper left corner of this box, indicate type of measurement with one of the following symbols: W-wading, C-cableway, B-bridge, M-motorboat, F-flume.

Number of sections--Count sections where velocity was measured but not zero.

Gage-height change--Show actual change from start to finish. Indicate whether net change was upward $(+)$ or down (-).

Time--List time from start to finish of measurement in tenths of an hour.

Measurement rated--Insert only one rating. Excellent (E), Good (G), Fair (F), Poor (P). Do not use E-G, G-F or F-P.

Water temperature--Enter to nearest 0.5 degrees $\mathrm{C}$.

Outside staff--Enter equivalent outside gage-height for measurement.

Max DPI or CSG--Enter peak gage-height registered by the Dahman peak indicator (DPI) or the creststage gage.

Remarks--Describe items that affect the interpretation of the record.

GH of Zero Flow--List if determined. 


\section{Continuous Record}

Surface-water gage-height data are collected as continuous record (hourly, 15-minute, or 5-minute values, for example) in the form of punches on paper tape, pen traces on graph paper, electronic storage such as data loggers, electronic transmissions by satellite, and cellular phone/modem. Streamflow records are computed by converting gage-height record to discharge record through application of stage-discharge relations. Ensuring the accuracy of gage-height record is, therefore, a necessary component of ensuring the accuracy of computed discharges.

Gage-height record is assembled for the period of analysis as completely as possible. Periods of inaccurate gage-height data are identified, then corrected (see the section "Datum corrections, gage-height corrections, and shifts") or deleted as appropriate. Items included in the assembly of gage-height record and procedures for processing the data are discussed by Kennedy (1983, p. 6) and Rantz and others (1982, p. 560 and p. 587).

Data are entered at the field or project office. Periods of missing record or "bad" record are replaced with data from backup recorders. When backup data are used, that portion of the record is thoroughly reviewed by a lead technician, FOC, or PC, unless the work was done by a journeyman-level technician. Gage-height record collected for use in the event of a failure of the principal recorder will not be saved unless it is actually used. The most common example of this is the A-35 graphic record obtained at manometer installations. After the Chief is satisfied with the record, usually after all records have been transmitted to Sacramento for publication, the unused back-up material should be thrown away. It is not to be put into the Federal Record Center.

Graphic record obtained on ice-affected streams should be retained if interpretation of the digital stage record is based on this graphic record. Other special needs for retaining backup record may arise. The Chief may retain any portion of the record at his discretion.

Notes on the A-35 chart pertaining to reversal corrections or any other corrections to the graphic record that is used should also be saved.

All personnel working records are provided training on all aspects of ADAPS by the DB Administrator. Follow-up training is provided "in-office" by the FOC or PC. The authority and responsibilities associated with long-term storage of surface-water data and ensuring the integrity of that historical data are discussed in the "Data-base Management" section of this report.

\section{Records and Computation}

Records computed for each station are often worked as a whole each year by a single individual. Records for each station are thoroughly checked if worked by personnel below journeyman level. A hydrographer that has demonstrated proficiency in stream gaging record computation should not require a 100-percent check on work produced. Removing a layer of review from those that have demonstrated competency will streamline the record production process. This results in greater employee empowerment, and direct accountability is where it belongs, on the competent worker. All records receive a summary review by the FOC, PC, or Lead Technician. Approximately 10 percent of all records are reviewed in detail by the SWS or QI staff. For new stations, when first-year records are worked, the FOC, PC, or Lead Technician is responsible for setting up all needed files. 


\section{Procedures for Working and Checking Records}

Procedures for ensuring the thoroughness, consistency, and accuracy of streamflow records are described in this section. The goals, procedures, and policies presented in this section are grouped in association with the separate components that are included in the records-computation process. Quality standards should be tempered by practical considerations of time and money resources. This applies only to revisions based on interpretations, and not to corrections of unquestionable errors. True errors are corrected regardless of their magnitude.

When reviewing surface-water records, daily discharges do not have to be revised unless the day in question would be changed by more than 10 percent, or if the monthly mean would be changed by 5 percent or more. If a FOC or PC wants to revise a record for lesser changes, that is his option; it is his assessment as to whether he can afford the time, and what the impact of the changes may be.

There may be frequent exceptions to the instruction. For certain key long-term stations, such as benchmark stations, we will require that the records be recomputed by the most accurate method possible, regardless of the percentage change.

Records of discharge, will be revised as needed to obtain the most accurate record possible.

Occasionally, a daily or monthly change may be less than that allowed, but because it covers an extended period, revision may be requested. A revision of a daily value with less than a 10 percent change may be required to avoid an illogical change of shape of the hydrograph. Other exceptions may occur; the policy is flexible, not absolute. We do not want to waste time on insignificant or debatable revisions, but neither do we want to compromise the integrity of our records.

\section{Gage height}

The accuracy of surface-water discharge records depends on the accuracy of discharge measurement, the accuracy of rating definition, and the completeness and accuracy of the gage-height record (OSW memorandum 93.07). Computation of streamflow records includes ensuring the accuracy of gage-height record by comparisons of gage-height readings made by use of independent reference gages, comparison of inside and outside gages, examination of high-water marks, comparisons of the redundant recordings of peaks and troughs by use of maximum and minimum indicators, examination of data obtained at creststage gages, and confirmation or updating of gage datums by levels.

Records computation includes examination of gage-height record to determine if the record accurately represents the water level of the body of water being monitored. Additionally, it includes identifying periods of time during which inaccuracies have occurred and determining the cause for those inaccuracies. When possible and appropriate, inaccurate gage-height record is corrected. When corrections are not possible, the erroneous gage-height data are removed from the set of data used for streamflow records computation.

\section{Gage height records and time changes}

Set the times of all electronic recorders to Pacific Standard Time and leave them there year-round. This affects all Electronic Dataloggers (EDL) and all data-collection Platforms (DCP). ADRs and graphic recorders are set to local time. 
It is National policy that data be stored in the ADAPS database in local time. Since DECODES has the ability to automatically convert to local time during conversion, all DECODES Site Definitions will be set to convert to local time. The only exception to this policy will be for special projects that have always stored their data in only PST in the past, or by special request for new projects that have not yet collected and stored data.

Note that it is NOT required that DCP times be set to UTC, even though the data we receive and process in SATIN is in UTC. The fact is that a DCP transmission does not contain a time tag, only data. The time is actually applied to the data when it is received at the downlink in Virginia before retransmission to us. Therefore, the only thing the instrument time does is control the time of DCP transmissions. Because all transmissions are on a four- hour cycle, the DCP time can be set to any four-hour offset of UTC - PST is an eight-hour offset to UTC.

\section{Levels}

Errors in gage-height data caused by vertical changes in the gage or gage-supporting structure can be measured by running levels. Gages can be reset or gage readings can be adjusted by applying corrections based on levels (Kennedy, 1983, p. 6).

Procedures for computing records for each station include ensuring that the front sheet has been completed for each set of levels, checking levels, ensuring that the level information was listed in the historical levels summary, and ensuring that information was applied appropriately as datum corrections. The individual computing the record is required to check field notes for indications that the gages were reset correctly by field personnel. If gages have not been reset to agree with levels, and the notes are not clear, a discussion with the Party Chief is suggested. If it is determined that the gage(s) should have been reset, a correction for the difference is applied to the gage-height record. The individual computing the records makes appropriate adjustments to the gage-height record by applying datum corrections.

\section{Ratings}

The development of the stage-discharge relation, also called the rating, is one of the principal tasks in computing discharge record. The rating is usually the relation between gage height and discharge (simple rating). Ratings for some special sites involve additional factors such as rate of change in stage or fall in slope reach (complex ratings) (Kennedy, 1983, p. 14).

District personnel follow procedures for the development, modification, and application of ratings that are described by Kennedy (1984). District personnel also follow guidelines pertaining to rating and records computation that are presented by Kennedy (1983, p. 14) and by Rantz and others (1982, Chap. 10-14 and p. 549).

For each gaging station, the most recent digital rating table can be obtained from a computer file. A graphical plot of the most recent rating can be obtained from file folders (original hand-drawn curve), or from computer files sent to an output device.

\section{Rating Curves}

To improve consistency in the development, drafting, and analysis of stage-discharge relations the following instructions are provided. For the purpose of this instruction, a stage-discharge relation (rating) is defined as a graph, an equation, or a table. 
A permanent rating curve master sheet (family of curves) will be established and maintained for each gaging station that has an unstable control. The initial master sheet should contain the fewer of all curves used for the last ten years or the last five curves. The plot should include the curve used for the peak of record. This curve compilation will provide a ready reference for shape and slope when developing new curves. Any new curves that cross or diverge (in mid- to high-flow ranges) require an explanation in the analysis. When these curve families are plotted, each family will be reviewed by the FOC or PC. Crossed curves, diverging curves, and mis-plotted points, should all be assessed for percent error and necessary revision. A plotting program is available to display the master curves. It is not a replacement for manual rating development. New ratings may be kept on a separate master sheet, but the scale should be identical to the initial sheet. All rating sheets should be kept together.

\section{Low flow rating}

At sites where flow approaches zero, rectilinear plotting of the rating is required. The method for developing low flow ratings in unstable channels is described by Kennedy (1984). This method utilizes the point of zero flow (PZF) obtained during streamflow measurements. The PZF should be obtained for every measurement if it is safe to do so. Exceptions are bedrock or concrete controls and lined channels. The accuracy of each determination of PZF should be rated. For example: PZF $=3.07+/-.02 \mathrm{ft}$.

\section{Scale Offset}

Ratings plotted on log-log paper have an intercept, curvature, and slope that are directly related to physical channel characteristics. Certain parts of a log-log rating and, occasionally, the entire curve can be linearized by adjusting the gage-height scale offset (e). The recommended procedure to determine a value for " $\mathrm{e}$ " is in Rantz and others (1982). A computer program is available to determine "e" on the Prime computer system, called "Offset". Once the curve or parts of it (not including overbank flow or extreme low flow) are linearized, the slope of the rating curve can be determined. Determining the slope of the curve in several places (straight-line segments only) is a good check on whether or not measurements were connected that should not have been, due to an intervening peak. A slope of 2.0 or less generally indicates channel control is effective.

\section{Curve smoothness}

A definition of smoothness of a rating is that first and second differences progress uniformly. The first differences should progress with each value (in most cases) larger than the one before, and with no uneven jumps. If the progression is not uniform, and the percentage between the computed versus expected discharge is more than 2 percent, it is necessary to adjust the input points. If there is a physical feature that causes a change in slope of the curve, it must be thoroughly described in the rating portion of the station analysis. The differences will only decrease with increasing stage when there is an actual reversal in the shape of the curve. Such reversals can only occur where some impeding effect on discharge occurs, such as backwater (Rantz and others, 1982, p. 555). First differences should be reviewed by the hydrographer developing the rating. 


\section{High flow portion of rating curves}

The high end of a rating curve should be drawn through any indirect measurement until better definition becomes available. All indirects for the current site and datum are to be shown on the current master curve sheet. Care should be taken to label whether the inside or outside gage height was used for plotting, if they differ appreciably. At least five high-water measurements defining the current conditions should be plotted. For stations with poor high-end definition (and all new stations), a step-backwater or other theoretical computation should be made to provide guidance in the general shape and slope of the rating curve.

The FOC or PC is ultimately responsible for ensuring that ratings are correctly developed, entered into the computer, checked, and stored. When personnel have questions pertaining to ratings, the FOC or PC is responsible for providing answers to their questions. The Surface Water Specialist or QI staff may be contacted at any time for assistance with rating development. New ratings are checked before copies of the ratings are sent outside the office.

\section{Datum corrections, gage-height corrections, and shifts}

A correction applied to gage-height readings to compensate for the effect of settlement or uplift of the gage is usually measured by levels and is called a "datum correction" (Kennedy, 1983, p. 9). Datum corrections are applied to gage-height record in terms of magnitude (in feet) and in terms of when the datum change occurred. In the absence of any evidence indicating exactly when the change occurred, the change is assumed to have occurred gradually from the time the previous levels were run, and the correction is prorated with time (Rantz and others, 1982, p. 545). Datum corrections are applied when the magnitude of the vertical change is equal to or greater than 0.015 foot.

A correction applied to gage-height readings to compensate for differences between the recording gage and the reference gage is called a "gage-height correction" (Rantz and others, 1982, p. 563). These corrections are applied in the same manner as datum corrections. Gage-height corrections are applied so the recorded data are made to agree with base-gage data. These corrections are applied when the difference between the recording gage and the base gage is equal to or greater than 0.02 foot. The correction should be applied only if there was little surge or little change in stage.

A correction applied to the stage-discharge relation, or rating, to compensate for variations in the rating is called a shift. Shifts reflect the fact that stage-discharge relations are not permanent but vary from time to time, either gradually or abruptly, because of changes in the physical features that form the control at the gaging station (Rantz and others, 1982, p. 344). Shifts can be applied to vary in magnitude with time and with stage (Kennedy, 1983, p. 35).

For many years the basic District policy concerning the shifting of ratings to discharge measurements was to make shift adjustments whenever a measurement plotted more than 5 percent from the rating use.

One problem in applying a constant 5-percent difference guideline is the variable accuracy of discharge measurements. As the rate of discharge measured decreases, the measurement accuracy generally decreases. For large flows, the number of vertical sections that can be measured is large, and 0.2 and 0.8 velocities may be obtained. As the flow decreases, the less accurate 0.6 method may have to be used. At low flows, the number of vertical sections may be greatly reduced, depths may be very shallow, and velocities may be too low or too high to measure with good accuracy. Consequently, a shift may be applied for a 5 -percent difference when the measurement error could be 10 percent or more. 
Table 1: Recommended guidelines for shifting

\begin{tabular}{cc}
\hline If discharge is & Shift if difference exceeds \\
\hline$>10 \mathrm{ft}^{3} / \mathrm{s}$ & 5 percent \\
1 to $10 \mathrm{ft}^{3} / \mathrm{s}$ & 7 percent \\
$<1.0 \mathrm{ft}^{3} / \mathrm{s}$ & 10 percent \\
\hline
\end{tabular}

These are only guidelines and may be disregarded if measuring conditions at a particular station suggest different shift guidelines. For instance, if an excellent low-flow measuring section is available, as in a flume section with little contraction and uniform velocities, then we may want to stay with the 5-percent guideline for all ranges of flow. On the other hand, if the measuring conditions are extremely poor (sluggish flow, large boulders, and angular velocities), a 10-percent difference might be a more realistic guideline for all ranges of flow.

Finally, consider the "balance" of measured differences from the rating. One measurement by itself may not warrant a shift because of a +3 percent difference from the rating, but three consecutive measurements all plotting +3 percent would indicate that a shift should be considered even though the 5-percent criteria has not been exceeded. A preponderance of measurements plotting to one side of the rating warrants a shift regardless of the perceived accuracy of the measurements or the relatively small magnitude of the shift.

Datum corrections, gage-height corrections, and shifts are documented in the station analysis, the output from ADAPS is inserted in the appropriate place in the analysis. Paper copies of calculations, notes and diagrams are maintained in the current folder. Checking transitions from one water year to the next is expected. Datum corrections and shifts (or rating application) on September 30 should be compatible with those used on October 1.

\section{Hydrographs}

A discharge hydrograph is a plot of daily mean discharges versus time. The date is aligned with the horizontal axis and the discharge is aligned with the logarithmic vertical axis. In the process of computing station records, this hydrograph is a useful tool in identifying periods of erroneous information, such as incorrect shifts or datum corrections. Additionally, hydrographs are helpful when estimating discharges for periods of undefined stage-discharge relation, such as during backwater or ice conditions, and in estimating discharges for periods of missing record.

Information placed on the hydrograph for each station includes station name, station number, water year, date the hydrograph was plotted, drainage area, plot of daily mean discharge data, plots of measurements, streamflow stations with which the hydrograph was compared, and any other information that may be of importance. Estimates may be made in red. The FOC or PC checks the hydrograph during the summary review. Hydrographs are also reviewed during a QI record review. 
The general procedures and goals of hydrographic comparison are outlined by Rantz and others (1982, p. 572 and p. 575). Hydrographs are filed with the primary record during the computation process and may be stored when computations for the water year are completed. There is no specific requirement to maintain a paper copy of the hydrograph. The FOC or PC provides guidance when there are questions concerning hydrographs. Historic hydrographs are stored in the National Archives. All hydrographs may be generated at need from the ADAPS data base.

\section{Station Analysis}

A complete analysis of data collected, procedures used in processing the data, and the logic upon which the computations were based is documented for each year of record for each station to provide a basis for review and to serve as a reference in case questions arise about the records at some future date (Rantz and others, 1982, p. 580). Topics discussed in detail in the station analysis (fig. 5) include equipment, hydrologic conditions, gage-height record, datum corrections, shifts, rating, discharge, special computations, remarks, and recommendations, (Rantz and others 1982, p. 582 and Kennedy 1983, p. 46). The station analysis is written by the individual who prepares the final update for the water year. Individuals who work portions of the computations for the year should write sections of the station analysis pertaining to the work they completed.

The checker is expected to discuss changes or corrections with the individual who worked the records. The FOC or PC holds the responsibility for resolving disputes. The record worker has the responsibility for ensuring that station analyses are prepared using the approved format. The FOC or PC are responsible for ensuring that an updated version resides in the correct computer directory. 


\title{
Example of Station Analysis
}

\author{
11316800 Forest Creek nr Wilseyville, CA \\ Surface-Water Station Analysis \\ 1994-95 WY
}

Equipment.--Sutron 8200 recorder with a Model 436B encoder driven by float tape in 36" CMP shelter and well, on left bank. There is a bank-operated cableway. Station description dated Feb. 6, 1993 is still applicable, including roadlog. Date of last visit by Field Office Chief is Oct. 3, 1994.

Gage-height record.--Record complete for year.

Datum and gage-height corrections.--No datum correction. Levels were last run Mar. 29, 1994.

Hydrologic conditions.--The drainage basin for this station ranges in elevation from 2,950 $\mathrm{ft}$ at the gage, to about 7,000 ft near the headwaters. Vegetation is mostly coniferous forest throughout the drainage, with minor amounts of grassland. The flow is unregulated, so flood peaks are usually caused by general storms. Smaller peaks come from snowmelt or small storms. Temperatures in the area are mild to warm in the summer and freezing in the winter. Severe winters could cause stage-discharge relationship to be affected by ice. Station is accessible at all times during the water year.

Rating.--The high water control is the natural channel. The low water control has scoured in recent years leaving the intakes in/on a riffle instead of in a gage pool. Because of this the control was built-up by adding boulders, cobbles and sand to create a gage pool over the intakes. The control is very unstable and allows much of the flow to pass through it. Rating 18, continued in use from last year, was applied to the Mar. 10 peak. New rating 19 was applied from the recession to the end of this water year. Ten discharge measurements were made during the water year, \#'s 384-393. Measurements covered a range in discharge from $1.47 \mathrm{ft}^{3} / \mathrm{s}$ to $646 \mathrm{ft}^{3} / \mathrm{s}$.

Discharge.--

Discharge.--

\begin{tabular}{ll}
\hline \multicolumn{1}{c}{ DATE } & \multicolumn{1}{c}{ SHIFT } \\
\hline Sept. 15 to Oct. 27 & +.20 constant shift \\
Oct. 27 to Jan. 9 & +.20 to +.21 prorated by time \\
Jan. 9 to Jan. 11 & +.21 to +.16 shifted by stage \\
Jan. 11 to Feb. 16 & +.16 to +.25 shifted by stage \\
Feb. 16 to Mar. 11 & +.25 to +.39 shifted by stage \\
Mar. 11 to Mar. 14 & +.39 to 0 shifted by stage \\
Mar. 14 to Sept. 30 & Rating applied direct. \\
\hline
\end{tabular}

Figure 5. Example station analysis. 


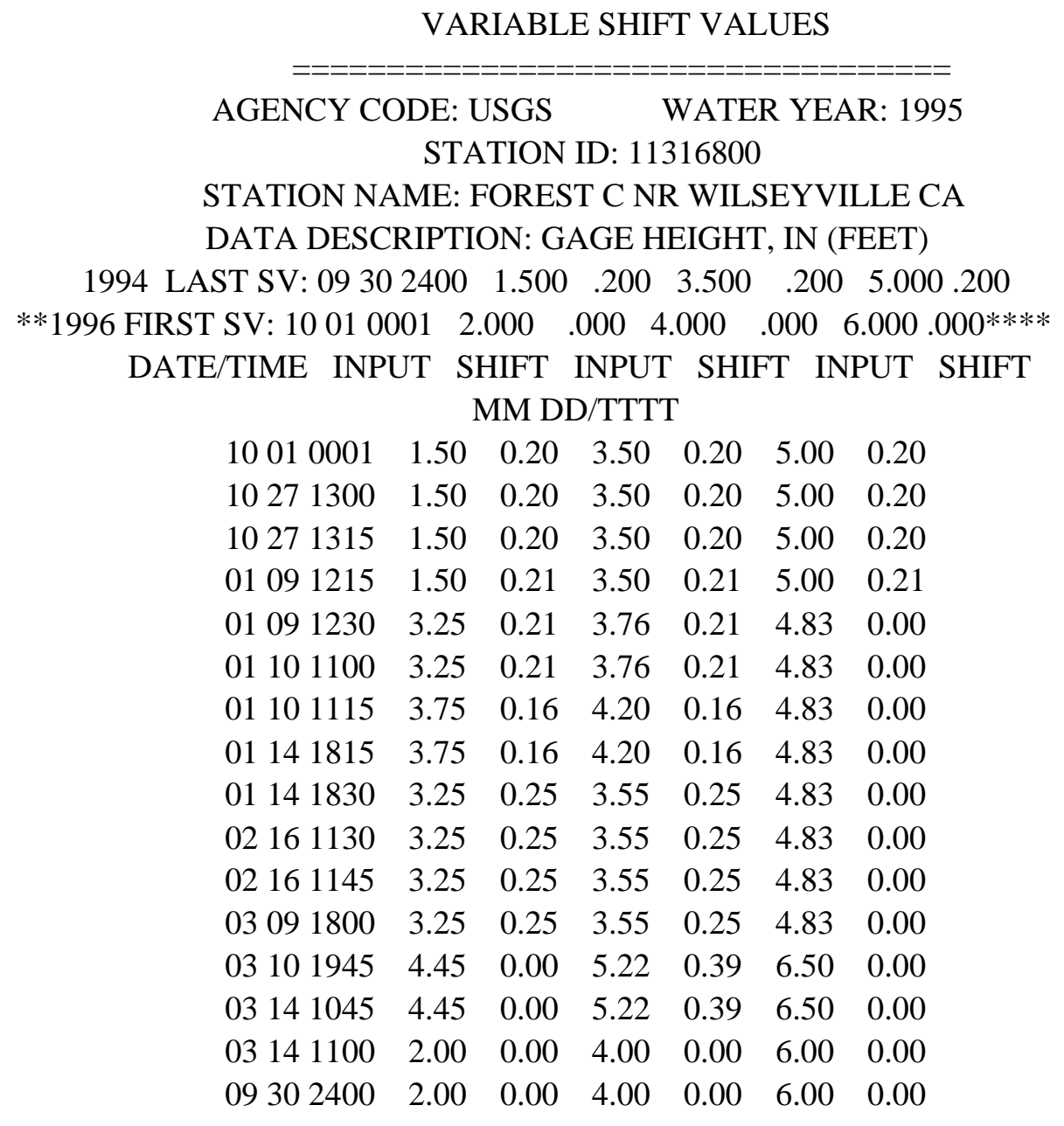

Remarks.--Records good. Hydrographic comparison with both M.F. Mokelumne and S.F. Mokelumne Rivers are fair. The purpose of this record is to measure Forest Creek's contributing flow to the M.F. of the Mokelumne River.

\author{
Written by: \\ E.D. Overrwood \\ $11 / 3 / 95$ \\ Reviewed by: \\ Andrew W. Stevens \\ $11 / 13 / 95$ \\ District Review: \\ Hienrich A. Richards \\ $3 / 27 / 96$
}

Figure 5. Continued 


\section{Winter Records}

Computing records that represent winter periods for gaging stations involves procedures that are not applicable to records that represent other times of the year. The formation of ice in stream channels or on section controls affects the stage-discharge relation by causing backwater; the effect varies with the quantity and nature of the ice, as well as with the discharge by (Rantz and others, 1982, p. 360). During some conditions the recorded gage-height data may be accurate, although the actual stage-discharge relation may be undeterminable and unstable. An example of this condition would be when surface ice forms on the stream, but the stilling well remains unfrozen and the water level in the stilling well represents the backpressure caused by the ice in the channel. During other conditions the recorded gage-height data are inaccurate, resulting in periods of missing gage-height record. An example of the latter would be when a stilling well or the intakes to the stilling well are frozen.

The individual computing the station record is responsible for identifying ice-affected periods and documents the situation in the gage-height paragraph of the analysis. Various methods may be used to estimate discharge during the period. These are described in either the discharge or special computations paragraphs. The individual also identifies periods of no gage-height record. Computed unit values are removed from computer files for periods of "bad gage-height record". The record worker is responsible for deleting the data.

\section{Furnished Records}

Surface-water data collected under the supervision of other agencies, organizations, or institutions are reviewed by various offices in the District. These data are published in the annual data report.

\section{Review of furnished records}

WRD Memo 85.129 is explicit in calling for the review of all furnished streamflow records published in the annual data reports. The reason is well stated in this excerpt:

"Publication by the USGS implies to users that such data meets the same accuracy standards and are of the same quality as those data collected by WRD. Therefore, it is the responsibility of each District to maintain appropriate quality-control procedures to ensure that furnished data meet the same accuracy standards as our own."

Any furnished record placed in a primary data descriptor in ADAPS or WATSTORE, whether for publication or not, must be reviewed and meet Survey standards. Instructions for the review of various types of furnished data are listed below:

1. Furnished daily discharge -- Review of furnished streamflow records should include inspection of discharge measurements and level notes. Rating curves, rating tables, and application of shifts also should be reviewed. Hydrographic comparison of records should be made when meaningful, and estimated periods of record must be carefully reviewed. Two discharge measurements, one during high or medium flow, and one during low-flow periods, should be made by Survey personnel each year. Both measurements may be made during the low-flow period, if in the judgement of the reviewing field office chief, the low-flow record accuracy is more critical than for high flows because of the need to verify stream-maintenance releases. 
2. Furnished reservoir records -- Field inspection notes for stage stations must be reviewed along with any recent level notes. Graphic charts and/or primary computation sheets, if there are any, should also be reviewed. Two visits per year to each reservoir gage should be made by Survey personnel. Levels should be run at least every 10 years by Survey personnel to document that the original datum has been maintained. There is usually no practical way to verify the accuracy of furnished storage capacity tables. Publication of contents should be avoided if there is evidence that capacity tables are more than 10 percent in error in the usable storage range. In these cases, reservoir elevations can be published in place of the contents. The decision to publish elevations instead of contents must be discussed with cooperators in advance. If reservoir contents are published, the date of the capacity table used should be shown in the manuscript.

Monthly reservoir evaporation records furnished by cooperators should be published with a disclaimer in the manuscript stating that these figures are unreviewed. Corrections from evaporation loss estimates, while of inherently poor accuracy, seldom exceed 5 percent of the unimpaired flow, and are at least a correction in the right direction.

3. Furnished periodic discharge records -- Some Federal Energy Regulatory Commission (FERC) licenses require periodic discharge measurements and staff-gage readings at certain sites. Copies of these measurements should be reviewed, and a USGS employee should make one measurement per year at the site, preferably in company with the FERC licensee hydrographer.

4. Furnished power plant records -- This type of record is very difficult to review, because methods of checking flow through penstocks and turbines are expensive and time consuming. If the record is the output of AVM or electromagnetic measuring equipment, then it probably is better than any other method available to measure the flow. No effort to verify these records will be made.

If the flow record is computed from electrical power output records, then every effort should be made to check the calibration with current-meter measurements, if possible. The reviewing office should have documentation on file for the conversion factors used to convert electrical power output to water discharge.

The above review procedures apply to all furnished records regardless of whether or not there is an intention to publish the record. There are some unpublished FERC records that have been entered into WATSTORE without any review. All furnished records, published or unpublished, will be placed in ADAPS or WATSTORE after review, for ease of retrieval and use with statistical programs.

DO NOT rate furnished records published in the annual data report. Our publication of a furnished record implies that the record is adequate and acceptable (Novak, 1985, WRD Data Reports Preparation Guide.) 
To maintain uniformity among field offices in the review of FERC streamflow and reservoir records the following instructions are provided.

1. Field review -- Survey personnel are to make two visits per year to FERC streamflow stations and reservoir gages. Field offices do not have the option of making only one measurement per year. If a field office will be unable to get both measurements, the field office chief is to notify the OC in a timely manner so that a substitute hydrographer can be sent. The timing of the visits is determined by the Field Office Chief, but at least one visit should be coordinated with the licensee so that the Survey's reviewer can observe the performance of the licensee's hydrographer to evaluate and develop an opinion about the licensee's ability and their equipment. It may not be possible to visit every station with a licensee's hydrographer each year, but it should be the goal. In planning the coordinated trips, the Survey representative should be the Field Office Chief or a senior technician. The joint inspection trips are vital to maintaining communication and cooperation.

2. Review of records -- FERC records should be reviewed twice a year. The first review should be made about the first of April, preferably in the office of the licensee's hydrographer. This is a good time to review new ratings and make corrections before too much work has been done. This can be a very casual review with a minimum of documentation. The final review occurs after the close of the water year and is the same type of review that the Survey Field Office Chiefs make for the records computed in their own offices, except that a brief write-up of review comments for each station must be prepared. Again, it is preferable to review the records in the licensee's office where all the original data and computations are available and questions can be readily answered. If this cannot be arranged, then the licensee will have to deliver the following material for each station to the reviewing field office:

o Daily values summary

o Hydrograph of daily discharges

o List of discharge measurements (9-207)

o Copies of front sheets for discharge measurements

o PC sheets (hourly gage-heights, shifts, datum corrections)

o Copy of any graphic record used for computation

o New rating tables and new rating curves

o Station analysis

3. Review standards -- In reviewing FERC records, the licensees are expected to maintain the same standards as the Survey in developing ratings, applying shifts, and datum corrections; there should be no double standard. The licensees all have computer programs capable of computing records equivalent to the Survey's. If a record is not worked properly, do not hesitate to request that it be reworked. For example, if the licensee (without explanation) neglects shifting to a measurement that is 10 percent off the rating, ask them to either apply a shift or justify disregarding the measurement. Measurements should not be thrown out just because measuring conditions were poor, if conditions are always poor at the particular site. Reasons for disallowing measurements must be critically evaluated, especially when records are used to document minimum flows mandated by law. Licensees usually are responsive, so be courteous, but firm about requesting changes that would be required in our own records.

\section{Daily Values Table}

With few exceptions, for each gaging station operated by the WRD a discharge value is determined and stored for each day. The daily values table generated by use of the records-computation software represents what discharge values are stored for each day of the water year. 
The daily values table is used during records computation to ensure the quality of the data. The table may be used to cross check values written on primaries or plotted on the hydrograph to ensure that proper discharge values have been stored. The table, retrieved from ADAPS, is loaded directly to the manuscript page. The annual report is considered to be the future reference; a Wordmarc file of the table and manuscript heading is maintained for one year and archived on tape.

\section{Manuscript and annual report}

When records computation for the water year has been completed and the data collected and analyzed by District personnel have been determined to be correct and finalized, the surface-water data for that water year are published along with other data in the District's annual data report, and/or on the World Wide Web (Internet). The annual data report is part of the series titled "U.S. Geological Survey Water-Data Reports." Information presented in the annual data report includes daily discharge values during the year, extremes for the year and period of record, and various statistics. Additionally, manuscript station descriptions are presented in the annual data report. Information contained in the manuscript includes physical descriptions of the gage and basin, history of the station and data, and statements of cooperation.

\section{Review of records}

In preparing the annual data report for publication, the District follows the guidelines presented in the report, "WRD Data Reports Preparation Guide," by Charles E. Novak, 1985 edition. To ensure that correct surface-water information is presented in the annual report, each manuscript page is reviewed by the FOC or PC. It is then transmitted electronically (using an automated system) to the assigned editor for the annual report. The editor rigorously reviews a random selection (about 10 percent). If any serious errors are discovered, they are brought to the attention of the responsible person. In addition, finding a significant error results in another, extra manuscript from that office being reviewed. When the editor is done, or a manuscript is not selected for review, the manuscript is transmitted to the QI section. The QI staff selects another 10 percent of records. The manuscript and all supporting documentation for the record is carefully reviewed. The Data Operations Chief is responsible for ensuring that surface-water information included in the annual report is correct.

The goal of the reviews is to ensure that proper methods were applied throughout the process of obtaining the surface-water data and computing the record. Another goal is to identify personnel that may be in need of further training. Basin comparisons are often considered part of this formal review process. Findings of the review(s) are either presented to the record worker orally or via written review commentary by the QI staff. The record worker is responsible for correcting deficiencies, and documenting corrective actions. If questions arise concerning the validity of the identified deficiencies, resolution of the problem is reached through discussion with the FOC, PC, Operations Chief, QI staff, or the Surface Water Specialist.

\section{District check list}

Offices vary in how a record of progress is maintained on discharge computation for each gaging station. California District offices find it helpful to have a check list for each station for each water year. Each office may use a custom check list as long as important items are not left out. This check list is a means of tracking the status of records computation for each station and ensuring that errors do not occur by omitting the necessary procedural steps. The check list is filed with the primary computations during the year. There is no need to maintain the completed check list after discharge records for each station have been finalized. 


\section{Crest-Stage Gages}

Records for crest-stage gages are computed with goals and procedures similar to those for other gaging stations. The field notes are examined for correctness and accuracy. Peak stages recorded by crest-stage gages are cross referenced with other available information; the dates of the peaks are determined by analyzing available precipitation data and peak data from recording gages within the same basin or from nearby basins.

A discussion of the policies and procedures used for field aspects of collecting data at crest-stage gages is included in this report in the section "Collection of Stage and Streamflow Data." The discussion in this section describes the analysis and office documentation of crest-stage data. This section does not pertain to data collected at crest-stage gages installed solely for the purpose of confirming peak stages at sites where manometer or pressure-transducer gages are used.

At sites where crest-stage gages are used to compute peak discharges, an initial stage-discharge relation, or rating, is developed for the site by direct or indirect high-water measurements. The rating is verified or adjusted on the basis of subsequent direct or indirect high-water measurements.

For each station, a list of all measurements is maintained, and each measurement is assigned a chronological number. For each station, a graphical plot of the current rating along with each recent and each notably high stage-discharge measurement is made readily available to those who check and review the station record by keeping a current plot in the station folder or by keeping a computerized version stored and readily produced through ADAPS. Current station descriptions and a summary of levels are maintained. A brief station analysis is written each year describing computation of the annual peak, identifying which rating was used and the type of flow condition, and describing how the dates of the peaks were determined.

Responsibility for ensuring the correct computation of annual peaks at crest-stage gages is held by the FOC or PC. Review of the crest-stage gage computations is treated the same as for a regular gaging station.

Responsibility for updating the Peak-Flow File promptly after peak data have been finalized is held by the FOC or PC. A current listing of annual peaks is maintained in the station folder for review purposes (OSW memorandum 88.07).

\section{OFFICE SETTING}

The FOC or PC is responsible for maintaining surface-water data and related information in a systematic and organized manner. This increases the efficiency and effectiveness of data-analysis and data-dissemination efforts. Good organization of files reduces the likelihood of misplaced information. Misplaced data and field notes can lead to analyses based on inadequate information, with a possible decrease in the quality of analytical results.

\section{Work plan}

Because the type of work, the amount of work, and the number of personnel vary greatly from one office to another, the manner in which a work plan is prepared also tends to vary. Duties are assigned and communicated to personnel by the FOC or PC in most cases. This is an informal system where duties are assigned verbally throughout the year. Individuals are assigned stations for which they are accountable by certain deadlines. 


\section{File Folders for Surface-Water Stations}

This section of the QA Plan describes the location and makeup of hard-copy files associated with surface-water data. Information pertaining to files maintained in computer storage can be found in the "Database Management" section of this report.

For each gaging station, a separate set of file folders is maintained and organized by station, preferably in downstream order. These folders are organized as "current files" and "backfiles." Current files and backfiles are grouped together by station. Extraneous items are removed from the current files after records are determined to be finalized each year. Backfiles are examined and extraneous items are removed after the records are published.

The set of current files for each station are grouped as follows:

Primary folders--The primary folders contain primary-computation printouts and graphed data of stage and discharge, recent measurement field note sheets, current level notes, rating tables, shift and datum correction tables, station analysis, 9-207, and may contain the station description. Data are grouped as a separate folder for each water year.

The set of backfiles is grouped for each station as follows:

Superceded Rating Tables, and Curve sheets

Superceded station descriptions, list of measurements

Correspondence folder, compilation files

The FOC or PC has responsibility for maintaining files in complete and proper order. Primary folders cannot be removed from the office.

\section{Field-Trip Folders}

A separate field folder for each field-trip area or project study area should be maintained. The primary purpose of these folders is to compile maps, station descriptions, station lists, and other pertinent information, allowing field personnel to run the trips effectively at a moment's notice and with a minimum of time spent on last-minute preparations. The field technician is responsible for updating the folders.

\section{Levels}

Level-note sheets are filed in chronological order in separate file boxes. Recent level notes are included in current file folders, then later filed in drawers or backfiles. Levels may be listed in the chronological summary preferably by station number in downstream order. Level notes for discontinued stations are archived.

\section{Station Descriptions}

Permanent copies of the surface-water station descriptions are maintained as computer files on the Prime system. A copy is kept in the current file folder. Individuals are expected to make updates in the computer files (which are available to everyone) whenever there is a significant change or every three years. The FOC or PC is responsible for ensuring that files are updated. (A list of files, sorted by year of update, may be obtained on request to the SWS or QI staff). A special directory is maintained for discontinued stations descriptions, OPERATIONS $>$ STA.DESC $>$ DISC. 


\section{Discontinued Stations}

Station descriptions, old analyses, old ratings, and other information are maintained at each field office. There are specific procedures personnel should follow in creating special files when stations are discontinued (J.A. Huff \& C.E. Lamb, U.S. Geological Survey, written commun., 1995). It is recommended that all documents for a discontinued station be sent to the Federal Archive Center.

When data-collection at a station is discontinued, the field or project office should transmit, by electronic mail, a "Notice of Discontinuance" (fig. 6) to the District DBM computer specialist with copies to the ADAPS data base administrator, Operations Chiefs, and the Quality Improvement Section. This form is located in a PRIME directory called:

\section{OPERATIONS $>$ DISC.STA $>$ DISC.FORM or}

in WordMARC document CREATE option. This form should contain the following:

a. Station number and name.

b. Type of data being discontinued such as surface water, water quality, sediment, temperature, etc.

c. Period of record, including breaks in record.

d. Effective date of discontinuance.

e. Cooperator at time of discontinuance.

f. Agencies notified of discontinuance--indicate cooperating and other outside agencies notified.

g. Reason for discontinuance.

h. Disposition of structures--indicate if gage house or cableway were removed, or if responsibility for these structures was transferred to another agency.

i. Disposition of equipment--indicate what equipment remains or was removed from the site, including recorders, wire weight gages, sediment box, samplers, etc. Indicate disposition of all controlled property.

j. Description of bench marks/staffs left to maintain datum.

$\mathrm{k}$. Record water years operated and location of office files, including station description, road log, and last used rating table.

1. Current property owner and permit authority.

m. Remarks--describe any problems if station were to be re-established, or any other comments thought to be of value now or later.

The DB Management computer specialist will put a copy of the final "Discontinuance" in the directory OPERATIONS > DISC.STA under a subdirectory for the specific field or project office and will update the District's Master List of surface-water sites to reflect the discontinuance. The ADAPS data base administrator will use the "Discontinuance" to make all necessary entries in the ADAPS system to discontinue pro cessing and storage of data for the site. 
Field Office

U.S. Geological Survey

Water Resources Division

NOTICE OF DISCONTINUANCE

Station number:

Station name:

Data being discontinued: Surface Water ( ) Sediment ( )

Water Quality ( ) Temperature ( )

Conductivity ( ) Other

Period of record:

Effective date of discontinuance:

Cooperator at time of discontinuance:

Agencies notified of discontinuance:

Reason for discontinuance:

Disposition/responsibility of structures:

Disposition of equipment:

Bench marks/staffs left for datum:

Station records for Water Years are filed in field office

or in files of

Current property owner:

Remarks:

Prepared by:

Date: _-_-

Figure 6. Example of Notice of Discontinuance. 


\section{Map Files}

Maps are organized according to the "California Index to topographic and other map coverage," first by latitude/longitude, then by the catalog number. Maps are available in Geological Survey standard 7.5 and 15 minute (1:24,000 and 1:62,500 scale) and 1:250,000 U. S. Army Map Service topographical. The DBM computer specialist is responsible for ensuring that the maps are maintained in good order. Base maps are allowed to be written on. The District base maps must stay in the office and are secured in locked cabinets. Personnel may order maps as required that can be used as work maps or maps that can be taken to the field.

\section{Archiving}

All WRD personnel are required to safeguard all original field records containing geologic and hydrogeologic measurements and observations. Selected material not maintained in field offices are placed in archival storage. Detailed information on what records have been removed to archival centers should be retained in the District or project office (WRD memorandum 77.83). The types of original data that should be archived include, but are not limited to, recorder charts and tapes, original data and edited data, observer's notes and readings, station descriptions, analyses, and other supporting information (WRD memorandum 92.59 and Hubbard, 1992, p. 12). At this time there is an agreement between WRD and the Federal Records Centers (FRC) of the National Archives and Records Administration to archive originaldata records (memorandum from the Chief, Branch of Operational Support, May 7, 1993).

Surface-water information is sent to the FRC from the California District approximately every 5 years. The FOC or PC is responsible for deciding what information is sent to the FRC, for ensuring that the information is properly packed and logged, and for ascertaining that the information is received by the FRC. Records of exactly what has been archived are maintained in a computerized relational data base by the Public Information Officer. Personnel who have questions concerning archiving procedures should first review the California District Archive Instructions booklet. If the answers are not found, they should ask the QI staff or Surface Water Specialist. Personnel who receive requests for information that require accessing archived records should refer the request to the District Public Information Officer, or obtain the requested records from archives with assistance from the PIO.

\section{Policy for Archiving Paper, Electronic, and other Data}

Division policy (WRD memorandum No. 92.59) requires that certain records be archived. This means systematic storage of records with suitable access, indexing, and uniformly high security. It is necessary to archive our records for several reasons:

-- Data for future research and investigations

-- Support of published reports

-- Support of working and on-line data bases

-- Security and accessibility of original data

-- Legal requirements or potential needs in legal matters

Part I, Federal Records Center Archival Procedure for Project Documents and Original Records; Part II, Archiving Electronic Data; and Part III, the District Archive. 
PART I. Federal Records Center Archival Procedure for Project Documents and Original Records

Part I pertains only to archiving documents and original field data that are recorded on paper. Each California District project leader shall be responsible for the preparation of certain documents and original field records for archiving. The following files, created at the start of the project and maintained throughout, will aid in the overall archival process:

A. Correspondence -- The purpose of this file is to provide a history of the plans, progress, accomplishments, and funding of the project and written report. The following documents will be filed:

--Program letters to cooperator(s)

--Cooperator approved project proposal

--Western Region approved project proposal

--Project work plan and quality-assurance plan

--Interim changes in project scope, funding, or objectives

--Summaries of cooperator meetings

--Record of important conversations with cooperator and advisors

--Report transmittal letters to cooperator(s)

B. Original Data Records -

1. Site-specific.-- An individual file will be created and maintained for any data site (well, spring, stream, estuary, lake, reservoir) where original field data were collected for the project. Once a site file is established, it will serve all future projects collecting data at that site.

At conclusion of project:

All surface-water data not routinely collected by a field office must be maintained in the project file. If the data are collected at a gaged site, they should be stored with the streamflow records for the same period.

2. Non-site-specific records.--Original field data collected for an area or group of sites. Some examples of these data types are water use, land use, geophysical surveys, leveling surveys, areal pumpage.

C. Data Analysis.-- This file category contains examples of significant final computations and assumptions that are not documented in reports. Types of analyses to be filed include:

--Statistical tools used

--Model documentation

--Worksheets (tables, graphs)

--Water budgets

--Pumpage estimates

--Estimates of aquifer parameters

--Notes to the record to assist future WRD investigators 
D. Project Status Reports -- This file will contain summaries of project reviews

Why we archive paper documents.--By law, no Federal record can be destroyed without authorization from the Archivist of the United States, and the vehicle for obtaining the authorization is a National Archives and Records Administration (NARA) approved records disposition schedule. Missionspecific schedules have been established for Water Resources Division records and are distributed to us by the USGS Paperwork Management Officer in Reston.

What to archive.--USGS Water Resources Division Mission-Specific Records Disposition Schedule gives descriptions and specific retention and disposal instructions for all types of project records. (Copies available from District Archive Specialist)

When to archive.--At conclusion of project (end of funding), the paper documents will be placed in the archival system. At that time, the project leader will:

(1) Submit above files A-D to the District Quality-Improvement and Data-Base Management Units for verification, then;

(2) Prepare records for transfer according to the Mission-Specific Records Disposition Schedule (consult with the District Archive Specialist for appropriate forms and specific instructions)

PART II. Archiving Electronic Data

WRD Memorandum 92.59 states that the recommendations made by the Data Policy Committee (Hubbard, 1992) have been accepted as official policy. That policy includes the following:

"The current policy in WRD is that all water data collected as part of the routine data-collection of the WRD (both basic and project data) must be stored in the computer files of the NWIS. One purpose of this policy is to enable all WRD work to be verifiable and repeatable to the greatest extent possible at any time in the future."

\section{PART III. The District Archive}

Not all records are accepted by the Federal Records Center (FRC) for storage. (See WRD MissionSpecific Records Disposition Schedule). Records that are not accepted by the FRC may be accepted by the California District Archive.

See your District Archive Specialist for records that fall into this category. Examples of records that are valuable and worth saving are non-original project material, historical maps, consultants' reports, environmental analyses, and data from other sources. 


\section{Communication of New Methods and Current Procedures}

All new, updated, or clarified policies are communicated to personnel involved with surface-water data-collection and analysis through oral and written communications. Time-critical information is disseminated via email. Otherwise, netnews, continuous and paper copies are sent to each office. Copies of all memorandums from WRD and OSW go to each office. It is the responsibility of FOC's, PC's, SWS, QI staff, and LT's to inform others of correct procedures. It is the responsibility of all personnel to ask questions in order to find out about such things.

\section{PUBLICATION OF SURFACE-WATER DATA}

The act of Congress that created the U.S. Geological Survey in 1879 (referred to as our organic act) established the Survey's obligation to make public the results of its investigations and research and to perform, on a continuing, systematic, and scientific basis, the investigation of the geologic structure, mineral resources and products of the National domain (U.S. Geological Survey, 1986, p. 4). Fulfilling this obligation includes the publication of surfacewater data and the interpretive information derived from the analyses of surface-water data.

\section{Publication Policy}

The USGS and WRD have created specific policies pertaining to publication of data and interpretation of those data. All WRD personnel, including those of this District, are required to abide by those policies. A brief summary of goals, procedures, and policies are presented in U.S. Geological Survey Open-File Report 87-0205 (1986, p. 437) All information obtained through investigations and observations by the staff of the USGS or by its contractors must be held confidential and not be disclosed to others until the information is made available to all, impartially and simultaneously, through Director-approved formal publication or other means of public release, except to the extent that such release is mandated by law (U.S. Geological Survey, 1986, p. 14). With the approval of the Director, hydrologic measurements resulting from observations and laboratory analyses, after they have been reviewed for accuracy by designated WRD personnel, have been excluded from the requirements to hold unpublished information confidential (U.S. Geological Survey, 1986, p. 15).

All interpretive writings in which the USGS has a proprietary interest, including abstracts, letters to the editor, and all writings that show the author's title and USGS affiliation, must be approved by the Director before release for publication. The objectives of the Director's review are to final-check the technical quality of the writing and to make certain that it meets USGS publication standards and is consistent with policies of the USGS and Department of the Interior. Director's approval ensures that (1) each publication or writing is impartial and objective, (2) has conclusions that do not compromise the USGS's official position, (3) does not take an unwarranted advocacy position, and (4) does not criticize or compete with other governmental agencies or the private sector (U.S Geological Survey, 1991, p. 10).

All data, including ground-water, surface-water, water-quality, sediment, and biological data collected in on-going data-collection programs or interpretive studies will be published in the Annual Data Report. The objective of this instruction is to make sure that all data collected are made available to the public. If the data gathered in support of a project would be better presented in a project report then the project advisor should notify the District Chief that the project data will be published separately, unless there is a specific project report that will include all the data. 
In general, any measurements made or samples collected and analyzed following Survey approved procedures are considered publishable data. Special data collected by unique, experimental, or nonstandard methods usually are published in interpretive reports, but can be accommodated in the Annual Report.

Data by other agencies generally should be avoided except for the work associated with the Federal Energy Regulatory Commission. Regardless of source, furnished records will not be published unless appropriate quality assurance review has been completed.

\section{Types of Publications}

Various types of book publications released by the USGS are available in which surface-water data and data analyses are presented. Publications of the formal series include the Water-Supply Paper, the Professional Paper, the Bulletin, the Circular, the Techniques of Water-Resources Investigations, Special Reports, and Selected Papers in the Hydrologic Sciences (U.S. Geological Survey, 1986, p. 42). Publications in the informal series include the Water-Resources Investigations Report, the Open-File Report, and the Administrative Report (U.S. Geological Survey, 1986, p. 52). Included in the Open-File Report series are data reports. Surface-water data collected by this District are published each year in a hydrologic data report that belongs to the annual series titled "U.S. Geological Survey Water-Data Reports." Factors considered by the District when deciding which form of publication should be utilized in presenting various types of information are presented by Green (1991, p. 14).

\section{Review Process}

Procedures for publication and requirements for manuscript review by WRD are summarized by U.S. Geological Survey (1991, p.36-41). This District fulfills those requirements for review and approval of reports prior to printing and distribution. All reports written by USGS scientists in connection with their official duties must be approved by the originating Division and the Director. At least two technical reviews of each report are required by WRD (U.S. Geological Survey, 1991, p. 36). Competent and thorough editorial and technical review is the most certain way to improve and assure the high quality of the final report (Moore and others, 1990, p. 24). Principles of editorial review and responsibilities of reviewers and authors are presented by Moore and others (1990, p. 24-49).

The following steps are taken to ensure the quality of the annual data report. Each manuscript page is reviewed by the FOC or PC. Approximately 10 percent of all pages of the report are reviewed by an editor. Approximately 10 percent of all pages are reviewed by QI or SWS. The District Reports Core Unit is responsible for the production of the final (print) copy and distribution of the annual report. All personnel involved in the annual report process are responsible for detecting deficiencies and for correcting or reporting any deficiencies.

\section{SAFETY}

Performing work activities in a manner that ensures the safety of personnel and others is of the highest priority for the USGS and the California District. Beyond the obvious negative impact unsafe conditions can have on personnel, such as accidents and personal injuries, they also can have a direct effect on the quality of surface-water data and data analysis. For example, errors may be made when an individual's attention to detail is compromised when dangerous conditions create distractions. So that personnel are aware of, and follow, established procedures and policies that promote all aspects of safety, the District communicates information and directives related to safety to all personnel by in-house training classes, memorandums, posters, videotapes, and email. It is the responsibility of each employee to remain current on First Aid and CPR certification. Each employee is expected to read the Safety and Environmental Health Handbook (445-1-H). 
An individual has been designated as Safety Officer by the District. Personnel who have questions or concerns pertaining to safety or who have suggestions for improving some aspects of safety, may direct those questions, concerns, and suggestions to their supervisor, the mentioned Safety Officer, a safety team, the Operations chief, or any senior District personnel.

The District has established a Safety team whose mission is to create an environment in which safety is incorporated in all District activities. The team has developed a Safety and Health Program, to be implemented through the following items.

1. Training - The California District will provide ongoing general training, both formally and on the job, along with required training and specific training related to potentially hazardous operations or procedures.

2. Promotion - Safety and health will be promoted by communication and enforcement of safety and health rules and practice.

3. Occupational Hazards and Industrial Hygiene and Inspections - Hazard inspections of buildings, vehicles, and equipment, and duty space to be used by employees will be conducted. Chemical-handling inspections will be completed, and deficiencies will be corrected.

4. Emergency Plan - Fire, earthquake, and other emergency situations will be addressed in written plans.

5. Environmental Safety - Chemical hygiene plans will be written. Facility compliance with federal, state, and local laws will be investigated.

6. Public Safety - All facilities will be maintained and inspected to ensure that the premises are safe for the employees and the public.

7. Accident/Incident Investigations, Reporting and Analysis - Accident and Incidents will be reported and tracked in order to ensure there is no trend, and prevention measures will be sought.

8. Safety Team Activities - The Safety Team will be an integral part of the California District's implementation and administration of the above plan. 
It is the policy of the California District, Water Resources Division of the U.S. Geological Survey to promote safety and health in our working environment. Because some employees of the California District must perform potentially unsafe duties in the scope of their work, we must establish safety measures to minimize the potential dangers and be constantly aware of those potential dangers. The goal is to create a work environment that is free from injuries or work-related illnesses. To meet this goal, EVERY employee must cooperate in detecting and controlling hazardous and potentially hazardous conditions. Any hazardous situation or practice must be immediately reported in writing to the employee's supervisor and the Safety Officer unless the employee feels that the hazardous condition poses an imminent danger to other employees or the public; then notification should be done by the most expeditious means. No employee shall be subjected to coercion, reprisal, restraint, discrimination, or other adverse actions as a result of reporting hazardous or potentially hazardous conditions.

In the work environment, there is always potential for illness and injury. Removal of preventable exposures to illness and injury is of primary importance and should always receive priority consideration over any operation. Management will provide all practical, physical, and educational resources to maintain personal health and safety. All employees must maintain a preventative and cooperative attitude relating to safety issues. Everyone will adhere to all safety-related policies, rules, and procedures and help ensure that any person on our premises or that works with us does the same.

\section{TRAINING}

Ensuring that personnel learn correct methods and procedures is a vital aspect of maintaining the quality of surface-water data and data analysis. By providing appropriate training to personnel, the District increases the quality of work and eliminates the source of many potential errors.

Training is provided for personnel by the District by in-house courses presented by the Surface Water Specialist, QI staff, and/or PC and FOC. The goals of training are many, but include improved understanding of physical processes, technical problems, statistical analysis, and more. Training needs are determined by individuals and their supervisors, through observation of the OC, SWS, QI staff, or management. The FOC and PC are responsible for ensuring that training is provided. The supervisor is expected to provide any needed on-the-job training and to schedule more formal training for personnel as needed. All personnel will attend the Level I training courses provided for surface water. In addition all field office personnel are expected to attend training on indirect measurements and instrumentation installation, calibration, and maintenance. When personnel identify training needs, they should contact their supervisor. When training has been obtained by individuals, that training is documented in personnel folders and in the District Training Data Base.

\section{SUMMARY}

Information included in this District Surface-Water Quality-Assurance Plan documents the policies and procedures of the California District that ensure high quality in the collection, processing, storage, analysis, and publication of surface-water data. Specific types of surface-water data discussed in this report include stage, streamflow, and basin characteristics. The roles and responsibilities of District personnel for carrying out these policies and procedures are presented, as are issues related to management of the computer data base and issues related to employee safety and training. 


\section{REFERENCES CITED}

Arcement, G.J., and Schneider, V.R., 1989, Guide for selecting Manning's roughness coefficients for natural channels and flood plains: U.S. Geological Survey Water-Supply Paper 2339, 38 p.

Barnes, H.B, 1967, Roughness characteristics of natural channels: U.S. Geological Survey Water-Supply Paper 1849, 213 p.

Beck, J.R., and Goodwin, C.R., 1970, Response of gas-purged manometers to oscillations in water level: U.S. Geological Survey Water-Supply Paper 1869-E, p. E1-E24.

Benson, M.A., and Dalrymple, Tate, 1967, General field and office procedures for indirect discharge measurements: U.S. Geological Survey Techniques of Water-Resources Investigations, book 3, chap. A1, 30 p.

Bodhaine, G.L., 1982, Measurement of peak discharge at culverts by indirect methods: U.S. Geological Survey Techniques of Water-Resources Investigations, book 3, chap. A3, 60 p.

Buchanan, T.J., and Somers, W.P., 1969, Discharge measurements at gaging stations: U.S. Geological Survey Techniques of Water-Resources Investigations, book 3, chap. A8, 65 p.

Carter, R.W., and Davidian, Jacob, 1968, General procedures for gaging streams: U.S. Geological Survey Techniques of WaterResources Investigations, book 3, chap. A6, 13 p.

Dalrymple, Tate, and Benson, M.A., 1967, Measurement of peak discharge by the slope-area method: U.S. Geological Survey Techniques of Water-Resources Investigations, book 3, chap. A2, 12 p.

Davidian, Jacob, 1984, Computation of water-surface profiles in open channels: U.S. Geological Survey Techniques of WaterResources Investigations, book 3, chap. A15, 48 p.

Edwards, T.K., and Glysson, G.D., 1988, Field methods for measurement of fluvial sediment: U.S. Geological Survey OpenFile Report 86-531, 118 p.

Green, J.H., 1991, WRD project and report management guide: U.S. Geological Survey Open-File Report 91-224, 152 p.

Hubbard, E.F., 1992, Policy recommendations for management and retention of hydrologic data of the U.S. Geological Survey: U.S. Geological Survey Open-File Report 92-56, 32 p.

Kennedy, E.J., 1983, Computation of continuous records of streamflow: U.S. Geological Survey Techniques of Water-Resources Investigations, book 3, chap. A13, 53 p.

1984, Discharge ratings at gaging stations: U.S. Geological Survey Techniques of Water-Resources Investigations, book 3, chap. A10, 59 p.

1990, Levels at streamflow gaging stations: U.S. Geological Survey Techniques of Water-Resources Investigations, book 3, chap. A19, 31 p.

Kilpatrick, F.A., and Schneider, V.R., 1983, Use of flumes in measuring discharge: U.S. Geological Survey Techniques of WaterResources Investigations, book 3, chap. A14, 46 p.

Lipscomb, S.W., 1995, Quality assurance plan for discharge measurements using broadband acoustic doppler current profilers: U.S. Geological Survey Open-File Report 95-701, 7 p.

Matthai, H.F., 1967, Measurement of peak discharge at width contractions by indirect methods: U.S. Geological Survey Techniques of Water-Resources Investigations, book 3, chap. A4, 44 p. 
Moore, J.E, Aronson, D.A., Green, J.H., and Puente, Celso, 1990, Report planning, preparation, and review guide: U.S. Geological Survey Open-File Report 89-275, 81 p.

Novak, C.E., 1985, WRD Data reports preparation guide: U.S. Geological Survey, 199 p.

Rantz, S.E., and others, 1982, Measurements and computation of streamflow, volumes 1 and 2: U.S. Geological Survey WaterSupply Paper 2175, 631 p.

Sauer, V.B., and Meyer, R.W., 1992, Determination of errors in individual discharge measurements: U.S. Geological Survey Open-File Report 92-144, 21 p.

Schroder, L.J., and Shampine, W.J., 1992, Guidelines for preparing a quality assurance plan for the district offices of the U.S. Geological Survey: U.S. Geological Survey Open-File Report 92-136, 14 p.

Shampine, W.J., Pope, L.M., and Koterba, M.T., 1992, Integrating quality assurance in project work plans of the U.S. Geological Survey: U.S. Geological Survey Open-File Report 92-162, 12 p.

Shearman, J.O., 1990, User's manual for WSPRO-- A computer model for water surface profile computations: U.S. Federal Highway Administration Report, FHWA-IP-89-027, 187 p.

Smoot, G.F., and Novak, C.E., 1968, Calibration and maintenance of vertical-axis type current meters: U.S. Geological Survey Techniques of Water-Resources Investigations, book 8, chap. B2, 15 p.

U.S. Geological Survey, 1986, Water Resources Division publications guide; Volume I, Publications policy and text preparation, $2 d$ ed., revised by D.W. Alt and K.T. Iseri: U.S. Geological Survey Open-File Report 87-0205, 429 p.

U.S. Geological Survey, 1991, Suggestions to authors of the reports of the United States Geological Survey, 7th ed., revised and edited by W.R. Hansen: U.S. Geological Survey special book publication, 289 p. 


\section{APPENDIX}

The following memorandums were cited in this report.

Office of Surface Water memorandum 93.12

Office of Surface Water memorandum 93.07

Office of Surface Water memorandum 92.11

Office of Surface Water memorandum 92.10

Office of Surface Water memorandum 92.09

Office of Surface Water memorandum 92.04

Office of Surface Water memorandum 91.09

Office of Surface Water memorandum 90.10

Office of Surface Water memorandum 90.08

Office of Surface Water memorandum 90.01

Office of Surface Water memorandum 89.08

Office of Surface Water memorandum 89.07

Office of Surface Water memorandum 88.18

Office of Surface Water memorandum 88.07

Office of Surface Water memorandum 87.05

Office of Surface Water memorandum 85.17

Office of Surface Water memorandum 84.05

Office of Surface Water memorandum 83.07

Surface Water Branch Memorandum 69-03

Water Resources Division memorandum 92.59

Water Resources Division memorandum 85.129

Water Resources Division memorandum 77.83

Memorandum from the Chief, Branch of Operational Support, May 7, 1993. 